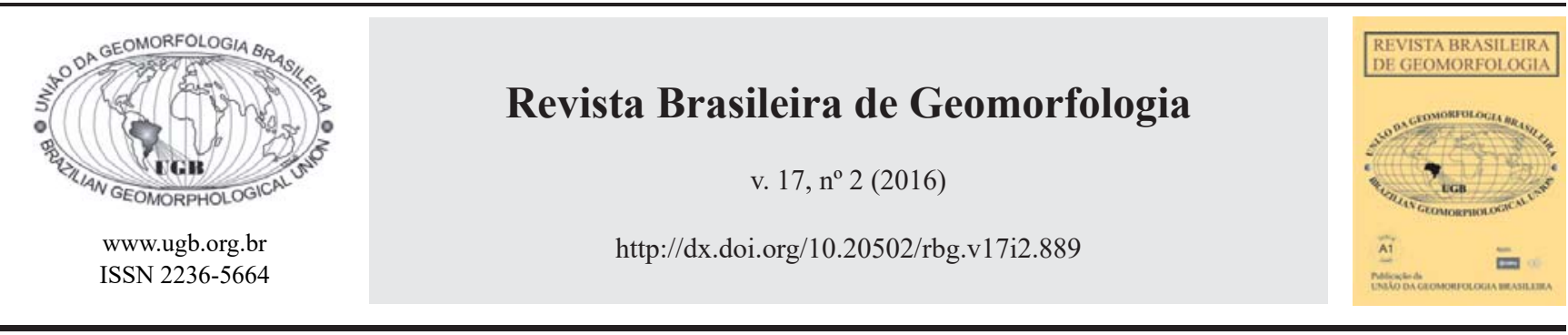

\title{
PADRÕES ESPACIAIS DO TRANSPORTE, PRODUÇÃO E VARIABILIDADE DE SEDIMENTOS SUSPENSOS DOS RIOS AMAZÔNICOS DE ÁGUAS BRANCAS
}

\author{
AMAZONIAN WHITE WATER RIVERS SPATIAL PATTERNS OF \\ SUSPENDED SEDIMENT TRANSPORT, YIELD AND VARIABILITY
}

\author{
Otávio Cristiano Montanher \\ Departamento de Tecnologia, Universidade Estadual de Maringá \\ Av. Dr. Ângelo Moreira da Fonseca, 1800, Umuarama, Paraná, CEP 87.506-370, Brasil \\ Email: otaviocmontanher@yahoo.com.br
}

Edvard Elias de Souza Filho

Departamento de Geografia, Universidade Estadual de Maringá Av. Colombo, 5790, Maringá, Paraná, CEP 87.020-900, Brasil

Email: eesfilho@uem.br

Evlyn Márcia Leão de Morais Novo

Divisão de Sensoriamento Remoto, Instituto Nacional de Pesquisas Espaciais Av. dos Astronautas, 1758, São José dos Campos, São Paulo, CEP 12.201-970, Brasil Email:evlyn@dsr.inpe.br

\begin{tabular}{l} 
Informações sobre o Artigo \\
\hline Recebido (Received): \\
15/11/2015 \\
Aceito (Accepted): \\
04/02/2016
\end{tabular}

Palavras-chave:

Sistemas Fluviais; Regime

Climático Amazônico;

Regressão Linear.

\section{Keywords:}

Fluvial Systems; Amazonian Climate Regime; Linear Regression.

\begin{abstract}
Resumo:
A produção e transporte de sedimentos suspensos são importantes processos geomorfológicos atuantes nos sistemas fluviais amazônicos, especialmente nos denominados Rios Amazônicos de Águas Brancas (RAAB). O estudo sintetizado neste artigo foca na representação e compreensão das variações espaciais do transporte de sedimentos desses rios. Este trabalho utilizou uma nova série de valores de concentração de sedimentos suspensos, estimados por meio de imagens do satélite Landsat 5/TM, para estender e preencher as séries de dados coletadas in situ. A partir dessa compilação de dados, foram geradas séries temporais de transporte de sedimentos suspensos para nove estações nos RAAB. Grandes rios amazônicos como o Amazonas, Solimões e Madeira possuem agora séries de aproximadamente 30 anos de dados de transporte de sedimentos suspensos de alta frequência temporal. Foram feitas análises sobre: i) diferenças regionais de produção e transporte de sedimentos; ii) variabilidade da produção de sedimentos nas escalas intranual e interanual; iii) relações entre variáveis espaciais, como latitude, longitude e área da bacia, e a produção de sedimentos e sua variabilidade. Os resultados obtidos permitem as seguintes conclusões em relação aos padrões espaciais e relações determinantes: i) quanto mais à jusante, e maior a área da bacia de drenagem, maior é o transporte de sedimentos, conforme uma relação
\end{abstract}


logarítmica; ii) enquanto o transporte de sedimentos suspensos é maior nas estações de jusante, a produção média das bacias possui um padrão contrário, sendo maior nas estações de montante; iii) considerando toda a bacia, os menores valores de produção de sedimentos concentram-se no período entre os meses de agosto e outubro, e o período que possui os maiores valores é entre janeiro e março. A região que produz a maior quantidade de sedimentos é a bacia do alto rio Madeira, em que grande parte da massa é transportada no período chuvoso, entre os meses de janeiro a abril. Esta bacia, no entanto, possui valores extremamente baixos nos meses secos; iv) as estações que estão no centro da bacia possuem uma menor variabilidade temporal, tanto interanual quanto mensal. As variabilidades anuais e mensais possuem uma forte relação e foram explicadas pelas mesmas variáveis (área de drenagem e longitude). Os coeficientes da regressão linear mostram que, quanto maior a área da bacia, e quanto mais a oeste, menor a variabilidade temporal da produção de sedimentos.

\begin{abstract}
:
Suspended sediment yield and transport are important active geomorphological processes of the Amazonian fluvial systems, particularly in the so called white water rivers (AWWR). The focus of the research summarized here is on the representation and understanding of the spatial differences of sediment transport of those rivers. This research used a new data series of suspended sediment concentration, estimated by means of Landsat 5/TM satellite images, to extend and to fill the in situ collected data sets. By using that data compilation, were generated temporal series of suspended sediment transport for nine AWWR stations. Currently, great rivers (like: Amazon, Solimões and Madeira) have high frequency suspended sediment transport series of approximately 30 years. Analysis was performed about the following topics: i) regional differences of sediment transport and yield; ii) intranual and interanual variability of sediment yield; iii) relationships among spatial variables (latitude, longitude and basin area) and sediment yield and its variability. The obtained results allowed the following conclusions in relation to the spatial patterns and determinants relationships: i) toward downstream, larger the drainage basin area and larger the sediment transport, which are described by a logarithmic relationship; ii) while the suspended sediment transport is larger in the downstream stations, the mean basin sediment yield has a contrary pattern, being higher in the upstream stations; iii) taking into account the whole basin, the smaller sediment yield values occur in the period from august to October, and the larger values occur in the period from January to March. The region that produces the bigger quantity of sediments is the upper Madeira basin, mainly in the rainy season, from January to April. However, that basin has extremely low sediment transport values in the dry months; iv) the stations placed in the center of the basin have a lower temporal variability, both interanual and intranual. Those variabilities have a strong correlation, being explained by the same variables (drainage area and longitude). The regression coefficients showed that, the larger the basin area, and the far to the west, smaller the temporal variability of sediment yield.
\end{abstract}

\section{Introdução}

Os rios amazônicos têm sido classificados como rios de águas pretas, claras (ou ligeiramente esverdeadas), e brancas (SIOLI, 1984; AB'SÁBER, 2008; JUNK et al., 2011; McCLAIN e NAIMAN, 2008). Essas águas possuem diferentes características limnológicas, como: ph, condutividade elétrica e concentração de nutrientes. Tais variações ocorrem em função de diferenças dos elementos geográficos de cada bacia hidrográfica específica, como o relevo, geologia, vegetação e clima (GIBBS, 1967; MARTINELLI et al., 1989; AB'SÁBER, 2008; McCLAIN e NAIMAN, 2008; FILIZOLA e GUYOT, 2009).
Uma das principais características que define os rios amazônicos de águas brancas (RAAB) é a alta concentração de sedimentos suspensos (SIOLI, 1984; McCLAIN e NAIMAN, 2008). Isso ocorre porque as cabeceiras de drenagem desses rios estão situadas principalmente no cinturão orogênico Andino, onde as taxas de soerguimento e de erosão são extremamente altas. Esses rios são os principais transportadores de sedimentos do sistema fluvial amazônico. Meade et al. (1985) e Meade (1994) estimaram que, entre 90 e $95 \%$ de toda a produção de sedimentos da bacia amazônica ocorre nos Andes, em concordância com Filizola e Guyot (2009), que estimaram a produção de sedimentos no restante da bacia hidrográfica, a partir de rios como 
o Tapajós e o Xingú, de apenas 7\%. Portanto, o estudo do transporte de sedimentos dos RAAB mostra praticamente o panorama global do fluxo de sedimentos na bacia amazônica.

O transporte e a deposição de sedimentos nos grandes rios amazônicos determinam muitas características desse sistema fluvial. O desenvolvimento em macroescala do relevo da bacia amazônica depende em grande parte da erosão fluvial (principalmente nos Andes) e das interações complexas entre água, sedimentos e as planícies de inundação nas regiões de planície (DUNNE et al., 1998; AALTO et al., 2006; BOOKHAGEN e STRECKER, 2010; CONSTANTINE et al., 2014). Com relação aos rios amazônicos meandrantes, Constantine et al. (2014) demonstraram que processos como a migração de meandros, o corte de pedúnculos e a criação de espaços para deposição de sedimentos nas planícies de inundação são mais ativos quanto maior o transporte de sedimentos do rio, de forma que a alteração de variáveis, inicialmente concebidas como muito importantes, como vazão e gradiente fluvial são pouco expressivas. Martinelli et al. (1989) mencionam o possível aumento do transporte de sedimentos devido às mudanças da cobertura do solo provocadas pelo desflorestamento. Lobo et al. (2014) demonstraram o aumento da produção e transporte de sedimentos em rios de águas claras em função das atividades de mineração.

Os trabalhos mencionados, até este ponto da introdução, realçam a importância da mensuração do fluxo de sedimentos dos rios amazônicos para a compreensão de processos geomorfológicos atuantes na bacia (atuais e pretéritos). Desde a década de 1960, muitas pesquisas foram feitas com relação ao estudo do transporte de sedimentos dos rios amazônicos (GIBBS, 1967; MEADE et al., 1979; MEADE et al., 1985; MARTINELLI et al., 1989; NITTROUER et al., 1995; DUNNE et al., 1998; GUYOT et al., 2005; FILIZOLA e GUYOT, 2009; MARTINEZ et al., 2009; FILIZOLA e GUYOT, 2011; GUYOT et al., 2011; ARMIJOS et al., 2013), em que boa parte teve como foco a estimativa do transporte de sedimentos anual total do rio Amazonas, em seu trecho inferior. Conforme mencionado por Filizola e Guyot (2009), pouco se conhece sobre o fluxo de sedimentos além da calha principal dessa bacia. Esses autores apresentam estimativas da produção de sedimentos para toda a bacia amazônica a partir de dados disponibilizados pela ANA (Agência Nacional de Águas), entre os anos de 1979 e 1998. No entanto, o protocolo de monitoramento é, em média, de três coletas da concentração de sedimentos suspensos (CSS) por ano, o que dificulta a obtenção de estimativas precisas do transporte anual total de sedimentos.

Além das coletas feitas pelas agências e instituições vinculadas à ANA, o ORE HYBAM (Environmental Research Observatory on Amazon Basin Hydrology, Geochemistry and Geodynamics) também realiza coletas, mas com uma frequência amostral de 10 dias, e também disponibiliza estimativas da CSS via dados de satélite (sensor MODIS). Essas séries, no entanto, são recentes e não possuem a abrangência espacial das estações da ANA. Visando a geração de séries temporais de CSS mais extensas e temporalmente refinadas, para uma melhor descrição e compreensão do fluxo de sedimentos de grandes rios amazônicos, Montanher (2013) e Montanher et al. (2014) geraram modelos para estimativa da CSS dos RAAB a partir de imagens do satélite Landsat 5/TM.

Neste trabalho, uma compilação de todas as bases de dados mencionadas (ANA, HYBAM e LANDSAT) foi feita para geração de séries temporais de transporte de sedimentos suspensos em nove estações nos RAAB. Grandes rios amazônicos como o Amazonas, Solimões e Madeira possuem agora séries em torno de 30 anos de dados de transporte de sedimentos suspensos de alta frequência temporal. Este artigo foca na representação e compreensão das variações espaciais do transporte de sedimentos desses rios. As principais questões que orientam a análise dos resultados são: Quais regiões da bacia produzem maior carga sedimentar? Qual é a variabilidade da produção de sedimentos nas escalas intranual e interanual? Qual é a relação entre variáveis espaciais, como latitude, longitude e área da bacia, e a produção de sedimentos e sua variabilidade?

A última questão mencionada, que visa a investigação de relações, busca compreender se apenas a posição espacial e a área da bacia, variáveis extremamente simples, são capazes de explicar a produção de sedimentos e sua variação temporal. Esta é uma abordagem que possui baixo teor analítico, pois os controles geológicos, geomorfológicos e climáticos em si não são diretamente avaliados. No entanto, o intuito é exatamente avaliar se existem padrões espaciais simples que expliquem a produção e variabilidade da produção de sedimentos. 


\section{Metodologia}

\section{1 Área de Estudo}

Foram utilizados dados de nove estações fluviométricas (Figura 1). A estação de Óbidos é a única no rio Amazonas e a mais à jusante entre todas as estações.
Cerca de $80 \%$ da bacia amazônica está à montante desse ponto do rio Amazonas. Os rios que drenam as regiões que estão à jusante de Óbidos são de águas claras e contribuem muito pouco em termos de carga sedimentar (NITTROUER et al., 1995; FILIZOLA e GUYOT, 2009).

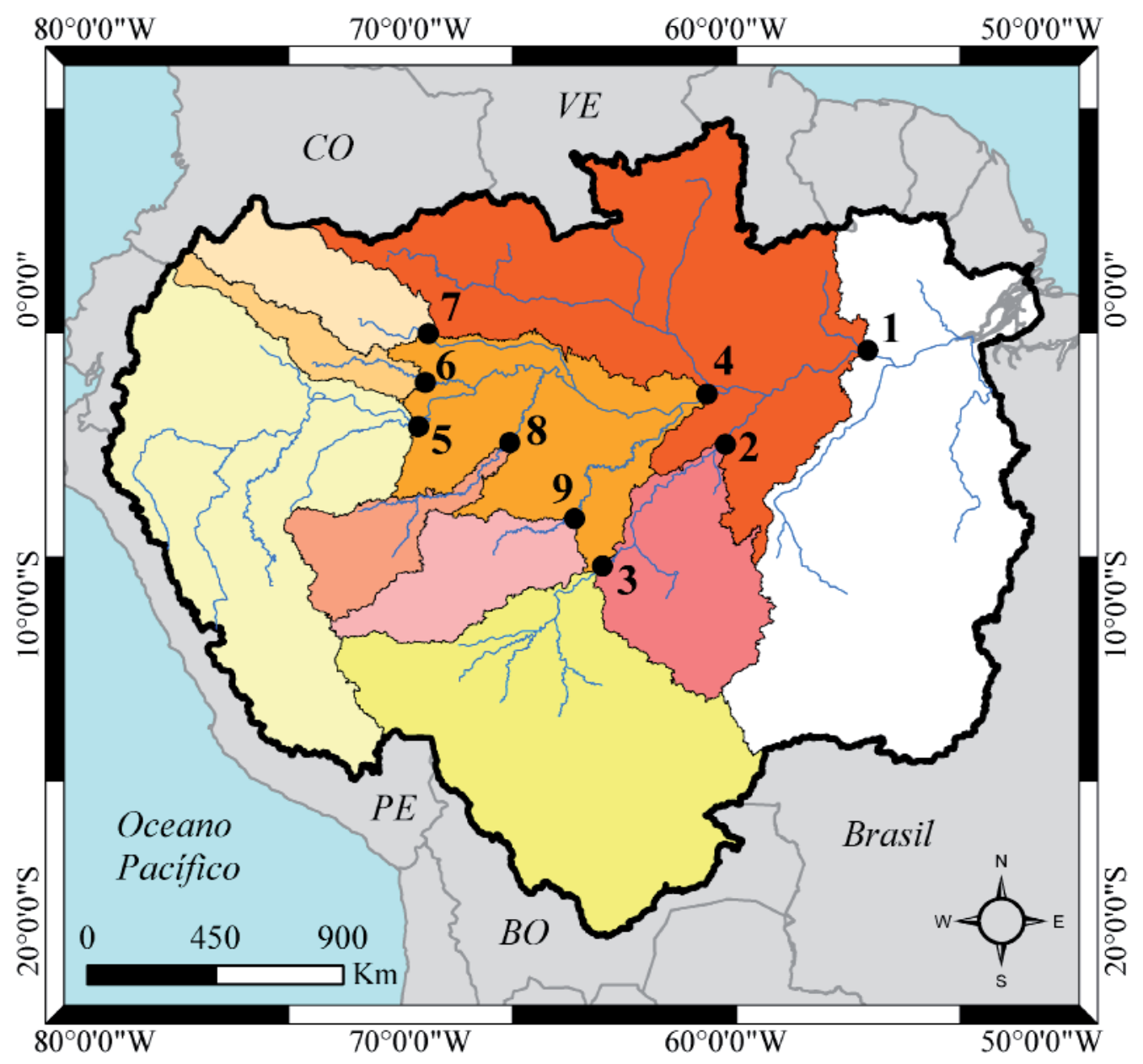

Figura 1 - Localização dos principais rios amazônicos, das estações utilizadas e suas respectivas bacias hidrográficas. 1 - Óbidos, rio Amazonas; 2 - Fazenda Vista Alegre, rio Madeira; 3 - Porto Velho, rio Madeira; 4 -Manacapuru, rio Solimões; 5 - Tabatinga, rio Solimões; 6 - Ipiranga Velho, rio Içá; 7 - Vila Bittencourt, rio Japurá; 8 - Gavião, rio Juruá; 9 - Lábrea, rio Purus. A linha em preto define a bacia hidrográfica amazônica. A área em branco é a região não avaliada neste estudo.

No rio Madeira há duas estações, de jusante para montante: Fazenda Vista Alegre e Porto Velho, assim como no rio Solimões, existem outras duas estações, de jusante para montante: Manacapuru e Tabatinga. Embora existam outras estações de monitoramento nos segmentos situados entre as duas estações de cada rio, optou-se por essas pelo fato de serem as que estão mais distante entre si e de possuírem as séries de dados mais completas. Adicionalmente, é interessante detalhar o comportamento espaço-temporal da produção sedi- mentar dessas duas bacias porque esses rios são os dois principais fornecedores de material sedimentar para o rio Amazonas, cada um contribuindo aproximadamente com metade do total (MEADE, 1994; FILIZOLA, 1999).

Outras quatro estações estão localizadas em afluentes do rio Solimões. Desses rios, dois drenam os Andes no Equador e na Colômbia: rio Içá (estação de Ipiranga Velho) e o rio Japurá (estação de Vila Bittencourt). Embora tais rios sejam importantes afluentes do 
rio Solimões, não são muito significativos em termos absolutos de produção de sedimentos de toda a bacia amazônica. No entanto, tais rios drenam uma porção da bacia que está sobre o Equador geográfico e em grande parte ao norte dele. Como tais regiões podem experimentar diferentes regimes climáticos quando comparadas com o restante da bacia (a sul), podem possuir diferentes regimes hidrossedimentológicos.

Por último, duas estações foram utilizadas em outros dois afluentes do rio Solimões: Gavião, no rio Juruá, e Lábrea, no rio Purus. Igualmente aos outros dois afluentes do rio Solimões, estes não possuem cargas excepcionais em relação ao total da bacia. No entanto, esses rios são de águas brancas, apesar de suas bacias hidrográficas estarem em regiões de relevo suave, não abrangendo os Andes. As cabeceiras de drenagem desses dois rios estão na região influenciada pelo Arco de Fitzcarraldo (RÄSÄNEN et al., 1987; ESPURT et al., 2007). Tais áreas estão sujeitas a um soerguimento regional (arqueamento) desde quatro milhões de anos antes do presente, o que têm provocado uma reorganização da drenagem, em formato radial, e têm levado à incisão dos canais devido ao rebaixamento do nível de base. Por causa dessa característica peculiar dessas drenagens, é interessante comparar sua produção sedimentar com os outros sistemas fluviais, com cabeceiras de drenagem nos Andes.

\subsection{Bases de dados}

Neste trabalho foram utilizadas bases de dados de CSS e de vazão da ANA e do ORE HYBAM. Adicionalmente, foram geradas novas séries de dados de CSS por meio de imagens Landsat 5/TM. Essas bases de dados não estão disponíveis para todas as estações, sendo que algumas possuem maior quantidade de dados do que outras (Tabela 1).

Tabela 1: Descrição das fontes de dados utilizadas para cada rio e estação

\begin{tabular}{ccrcrr}
\hline Rio & Estação & $\begin{array}{c}\text { Área da } \\
\text { bacia }\left(\mathrm{km}^{2}\right)\end{array}$ & $\begin{array}{c}\text { Concentração de } \\
\text { sedimentos suspensos }\end{array}$ & Vazão & $\begin{array}{c}\text { Imagens } \\
\text { Landsat 5 }\end{array}$ \\
\hline Amazonas & Óbidos & 4.670 .000 & ANA/LANDSAT/HYBAM & HYBAM & 308 \\
\hline Içá & Ipiranga Velho & 107.000 & ANA/LANDSAT & ANA/IDEAM* & 671 \\
\hline Japurá & Vila Bittencourt & 206.000 & ANA/LANDSAT & ANA & 639 \\
\hline Juruá & Gavião & 164.000 & ANA/LANDSAT & ANA & 471 \\
\hline Madeira & Porto Velho & 976.000 & ANA/LANDSAT/HYBAM & HYBAM & 540 \\
\hline Madeira & Fazenda Vista Alegre & 1.310 .000 & ANA/LANDSAT/HYBAM & ANA/HYBAM & 611 \\
\hline Purus & Lábrea & 226.000 & ANA/LANDSAT & HYBAM & 589 \\
\hline Solimões & Tabatinga & 874.000 & ANA/LANDSAT/HYBAM & HYBAM & 757 \\
\hline Solimões & Manacapuru & 2.200 .000 & ANA/LANDSAT/HYBAM & ANA/HYBAM & 823 \\
\hline TOTAL & - & - & & - & $\mathbf{5 4 0 9}$ \\
\hline
\end{tabular}

* O IDEAM é um instituto colombiano (Instituto de Hidrologia, Meteorología y Estudios Ambientales, www.ideam.gov.co), que disponibiliza dados sob demanda. O pedido $n^{\circ} 20141128135523$ foi feito para a estação de “Tarapaca” a qual dista aproximadamente $40 \mathrm{~km}$ (via fluvial) à montante da estação de Ipiranga Velho, no mesmo rio, o qual é denominado Putumayo em território colombiano. Os dados dessa estação foram utilizados para preenchimento de falhas da série histórica da estação de Ipiranga Velho.

A ANA disponibiliza dados coletados a partir de uma série de estações instaladas na rede hidrográfica amazônica, operadas por diversas instituições. Essas estações medem principalmente a cota fluvial, posteriormente relacionado-a com a descarga fluvial (ou vazão) por meio de curvas-chave. Em menor número e frequência amostral, a ANA também disponibiliza dados de CSS.
Até o início da década de 1980, os poucos dados existentes (valores de CSS, da ANA) referem-se a coletas realizadas próximo à superfície d'água, entre 40 e $400 \mathrm{~cm}$ (FILIZOLA e GUYOT, 2009). Após esse período, as coletas passaram a ser feitas a partir da integração em profundidade, em concordância com protocolos e agências internacionais, em que o valor representa a média do perfil (FILIZOLA e GUYOT, 
2009). Ainda segundo os autores, a estação de Óbidos, no rio Amazonas, é a única que continua a coletar a água em superfície para posterior filtragem.

O projeto HiBAm e o programa ORE HYBAM são iniciativas de pesquisa que envolvem, além da França, diversos países que abrangem a região amazônica (Brasil, Peru, Colômbia, Equador, Bolívia e Venezuela). O ORE HYBAM é um programa de longo prazo para avaliação de processos de transporte de matéria na bacia amazônica (FILIZOLA et al., 2011). Os principais focos do programa são na compreensão: da transferência de massa da bacia amazônica para o oceano Atlântico; da sensitividade da transferência de massa às variações climáticas e antropogênicas; e do papel das áreas úmidas na transferência de massa (FILIZOLA et al., 2011). O programa opera em cooperação com instituições de pesquisas e agências nacionais, (como a ANA, no Brasil), gerando um conjunto de dados independente.

São coletados, a partir do programa ORE HYBAM, dados diários de hidrologia, dados de CSS a cada 10 dias e dados mensais físico-químicos e de geoquímica em 15 estações de amostragem nos principais grandes rios amazônicos. Os dados são livremente disponibilizados a partir do endereço eletrônico: www. ore-hybam.org. Foram utilizados dados diários de vazão e dados de CSS coletados in situ, com frequência amostral de 10 dias.

Ao contrário da maioria dos dados disponibilizados pela ANA, no caso desse programa as coletas d'água para determinação da CSS são feitas em superfície (em torno de $20 \mathrm{~cm}$ de profundidade), em amostras de 500 $\mathrm{ml}$, em um ponto fixo do rio (MARTINEZ et al., 2009). Os procedimentos para determinação da CSS são rotineiros, incluindo filtragem da água (via filtros de $0,45 \mu \mathrm{m}$ de tamanho do poro) e secagem e pesagem dos filtros, assim como no caso dos dados da ANA. O programa também fornece estimativas da CSS via imagens orbitais compostas de oito dias do sensor MODIS. As pesquisas de Martinez et al. (2009), Espinoza Villar et al. (2012) e Espinoza Villar et al. (2013) utilizaram esses dados.

Além das bases de dados já existentes, este trabalho utilizou novas estimativas de CSS geradas a partir de produtos do Sensoriamento Remoto. Isto pode ser feito a partir da premissa de que a reflectância espectral varia em função da CSS. Portanto, as medidas radiométricas feitas em nível orbital podem fornecer uma estimativa do nível de CSS para um determinado tempo e local a partir de equações previamente ajustadas. Para os RAAB, Montanher et al. (2014) geraram modelos para estimativa da CSS a partir de imagens do satélite Landsat 5/TM.

Foi feita uma busca por imagens do sensor TM que abrangem as estações utilizadas para caracterização do transporte de sedimentos dos rios em estudo. Todas as imagens utilizadas foram obtidas gratuitamente a partir do banco de dados do INPE (Instituto Nacional de Pesquisas Espaciais), por meio do endereço eletrônico: www.dgi.inpe.br/CDSR/. Os detalhes da aplicação do método e da geração das estimativas podem ser consultados em Montanher (2013) e Montanher et al. (2014). A localização das cenas utilizadas, no contexto da bacia amazônica, pode ser observada na Figura 2.

\subsection{Quantificação do transporte de sedimentos suspensos}

Alguns dados de CSS das bases descritas no tópico anterior referem-se a coletas feitas na superfície d'água. Para o cálculo do transporte de sedimentos, no entanto, é preciso normalizar a variação vertical da CSS nas seções. Isto é necessário, pois Laraque et al. (2005), Meade (2007) e Kilham e Roberts (2011) observaram grandes variações da CSS, em que, quanto maior a profundidade, maiores os níveis de CSS. No entanto, têm sido observadas relações lineares adequadas entre os valores de CSS em superfície (CSSS) e os valores integrados em profundidade (CSS).

Como os tipos de sedimentos (composição, densidade, forma) e a hidrodinâmica fluvial variam localmente, o ideal é que cada estação possua uma equação ajustada. Martinez et al. (2009) fez uso de uma equação ajustada para o rio Amazonas (em Óbidos), em que 18 campanhas de campo foram realizadas entre 1995 e 2003 para relacionar a CSSS e a CSS. Laraque et al. (2005) apresentam uma série de equações para relacionar a CSSS com a CSS para diversas estações de amostragem do programa HYBAM. As equações utilizadas para estimativa da CSS integrada para o perfil estão descritas na Tabela 2.

A Tabela 2 apresenta equações apenas para cinco estações porque o protocolo de amostragem d'água da ANA, para o cálculo da CSS, é para todo o perfil. Por essa razão, os dados das estações nos rios: Içá, Japurá, Juruá e Purus (que não possuem monitoramento contínuo pelo programa HYBAM), não precisam passar 
Tabela 2: Equações para estimativa da concentração média de sedimentos suspensos integrada em profundidade

\begin{tabular}{c|c|c|c} 
& & & \\
\hline Amazonas & Óbidos & Martinez et al. (2009) & CSS $=$ CSSS $\times 1,24+43,5$ \\
\hline Solimões & Manacapuru & Laraque et al. (2005) & CSS $=$ CSSS $\times 1,08+73$ \\
\hline Solimões & Tabatinga & Laraque et al. (2005) & CSS $=$ CSSS $\times 0,98+130$ \\
\hline Madeira & Fazenda vista Alegre & Laraque et al. (2005) & CSS $=$ CSSS $\times 1,72+38$ \\
\hline Madeira & Porto Velho & Laraque et al. (2005) & CSS $=C S S S \times 1,5+9$ \\
\hline
\end{tabular}

por esse procedimento. Adicionalmente, os modelos desenvolvidos para o satélite Landsat 5 também foram desenvolvidos para essas estações com base em valores integrados em profundidade, portanto esses também não precisam ser extrapolados.

O transporte de sedimentos é obtido por meio da multiplicação da CSS $(\mathrm{mg} / \mathrm{l})$ pela vazão $\left(\mathrm{m}^{3} / \mathrm{s}\right)$, valor posteriormente multiplicado para um período de tempo (por exemplo, $1 \mathrm{dia}=86400$ segundos). Os dados de vazão são diários, mas os dados de CSS não possuem essa frequência amostral. Embora a base de dados utilizada neste trabalho tenha uma alta frequência temporal, com média global de uma coleta a cada 11,46 dias (Tabela 3), é necessário realizar interpolações para geração de uma base diária de CSS. Portanto, após a integração da CSSS em profundidade, os valores de CSS para os dias que não possuem dados foram obtidos por meio da seguinte equação:

$$
\operatorname{CSSS}_{n}=\frac{\operatorname{CSSS}_{f}-\operatorname{CSSS}_{i}}{d_{f}-d_{i}}\left(d_{n}-d_{i}\right)+\text { CSSS }_{i}
$$

Em que:

$d$ = dia juliano;

$\operatorname{CSSS}_{n}=$ CSSS para um dia qualquer $d_{n}$

$\operatorname{CSSS}_{i}=$ CSSS para um dia inicial $d_{i}$ anterior à $d_{n}$; CSSS $_{f}=$ CSSS para um dia final $d_{f}$, posterior à $d_{n}$.

Após esses procedimentos, foram obtidas séries diárias de transporte de sedimentos suspensos. Os totais mensais e anuais de transporte de sedimentos foram obtidos a partir da soma desses valores diários. As séries possuem uma extensão temporal média de 28,77 anos (Tabela 3), em que a série mais curta possui 26 anos (rio Japurá) e a mais longa possui 33 anos (rio Madeira, Porto Velho).

Tabela 3: Descrição das séries temporais dos dados utilizados para o cálculo do transporte de sedimentos suspensos em cada rio e estação

\begin{tabular}{ccccrr}
\hline Rio & Estação & Período & $\begin{array}{c}\text { Anos } \\
\text { hidrológicos } \\
\text { completos }\end{array}$ & $\begin{array}{c}\text { Frequência } \\
\text { amostral } \\
\text { (dias/coleta) }\end{array}$ & $\begin{array}{c}\text { Valores de } \\
\text { concentração de } \\
\text { sedimentos suspensos }\end{array}$ \\
\hline Amazonas & Óbidos & $9 / 4 / 1984-23 / 4 / 2015$ & 30 & 7,25 & 1563 \\
\hline Içá & Ipiranga Velho & $17 / 4 / 1984-26 / 2 / 2014$ & 27 & 14,58 & 748 \\
\hline Japurá & Vila Bittencourt & $15 / 4 / 1984-13 / 11 / 2011$ & 26 & 15,37 & 655 \\
\hline Juruá & Gavião & $5 / 5 / 1984-7 / 7 / 2014$ & 27 & 19,71 & 559 \\
\hline Madeira & Porto Velho & $6 / 5 / 1981-14 / 9 / 2014$ & 33 & 7,45 & 1634 \\
\hline Madeira & Fazenda Vista Alegre & $30 / 4 / 1984-$ & 30 & 6,79 & 1647 \\
\hline Purus & Lábrea & $27 / 12 / 2014$ & 28 & 16,59 & 665 \\
\hline Solimões & Tabatinga & $18 / 2 / 1984-13 / 11 / 2011$ & 27 & 9,29 & 1090 \\
\hline Solimões & Manacapuru & $21 / 7 / 1983-1 / 5 / 2015$ & 31 & 6,17 & 1881 \\
\hline MÉDIA & - & - & $\mathbf{2 8 , 7 7}$ & $\mathbf{1 1 , 4 6}$ & 1160 \\
\hline
\end{tabular}




\subsection{Mapeamento da produção de sedimentos}

Foram feitos diversos mapas que representam as variações espaciais da produção e do transporte de sedimentos na bacia. Esses mapas estão diferenciados primeiramente conforme a escala temporal de análise: anual ou mensal. Com relação aos valores anuais, foram elaborados três mapas: o primeiro apresenta os valores médios de transporte de sedimentos, sua variabilidade foi representada em um segundo mapa e o terceiro apresenta a produção de sedimentos.

O transporte anual refere-se ao transporte médio absoluto ao longo de um ano hidrológico completo, e sua unidade é em massa/ano. Ainda em relação a essa variável, foi elaborado outro mapa, que apresenta sua variabilidade. Essa variação interanual foi calculada a partir da seguinte equação:

$$
\sigma^{\text {norm }}=\left(\frac{\sigma}{\mu}\right) \cdot 100
$$

em que:

$\sigma^{\text {norm }}=$ desvio padrão normalizado do transporte anual de sedimentos, em escala de porcentagem;

$\sigma=$ desvio padrão do transporte anual de sedimentos (ton/ano);

$\mu=$ transporte de sedimentos anual médio (ton/ano);

Por sua vez, o cálculo da produção de sedimentos leva em conta a área de drenagem à montante de uma determinada estação:

$$
P=\frac{T}{A}
$$

em que:

$\mathrm{P}=$ produção de sedimentos, considerando a área à montante de uma estação qualquer (massa/área/tempo); $\mathrm{T}=$ transporte de sedimentos estimado em uma estação (massa/tempo);

$\mathrm{A}=$ área de drenagem à montante da estação $\left(\mathrm{km}^{2}\right)$.

A unidade do transporte de sedimentos é massa (ton) por tempo, o qual foi adotado em mês e ano, enquanto que a área é dada $\mathrm{em} \mathrm{km}^{2}$, cujos valores são fornecidos pela ANA e estão apresentados na Tabela 1 . Portanto, a produção (P) é uma determinada massa que foi transportada em um intervalo de tempo, normalizados em uma área (ton $/ \mathrm{km}^{2} /$ mês ou ton $/ \mathrm{km}^{2} / \mathrm{ano}$ ).

Em relação aos valores mensais, também foram produzidos três mapas. O primeiro refere-se aos valores médios de produção de sedimentos para cada mês do ano, calculado segundo a equação 3 . A unidade descrita nessa equação refere-se aos valores absolutos de produção de sedimentos. Entretanto, a representação visual das variações mensais dessa variável é dificultada pela grande diferença em termos de magnitude que existem entre as estações. Os rios Içá, Japurá, Juruá e Purus possuem transporte de sedimentos muito mais baixo do que os rios Madeira, Solimões e Amazonas. Portanto, quando a escala absoluta é utilizada, essas áreas aparecem com baixos valores praticamente o ano todo. Propõem-se então, para demonstração da variação sazonal específica de cada estação, a seguinte normalização:

$$
P^{\text {norm }}=\left(\frac{P^{m}}{P_{\max }^{m}}\right) \cdot 100
$$

em que:

$P^{\text {norm }}=$ produção de sedimentos normalizada, em escala de porcentagem;

$P^{m}=$ produção de sedimentos de um mês qualquer;

$P^{m \_ \text {max }}=$ produção de sedimentos do mês de maior valor médio.

Para exemplificação, o mês de maior produção média da estação de Porto Velho, no rio Madeira, é março, com 109,69 ton/km/mês. Quando a normalização é aplicada, o mês de março passa a ser $100 \%$ e todos os outros meses possuem valores menores, por exemplo, em setembro, o mês de menor produção, torna-se $2,35 \%$. Dessa forma, os valores de todas as estações são comparáveis (entre 0 e $100 \%$ ), sendo possível notar tanto o período do ano em que cada estação tem seu pico de transporte quanto sua amplitude em relação aos períodos de menor transporte.

Um terceiro mapa ainda foi elaborado para representação da variabilidade mensal da produção de sedimentos das estações. O cálculo é o mesmo apresentado na equação 2 , mas ao invés de ano, a unidade temporal de intervalo adotada são os meses.

\subsection{Análise de regressão}

Para avaliar a relação entre variáveis espaciais e a 
produção de sedimentos e sua variabilidade, foi utilizada a análise de regressão. As variáveis consideradas como explicativas são: latitude e longitude médias da bacia e suas áreas. Inicialmente foram feitas análises univariadas, o que permite a avaliação da relação entre cada variável dependente e independente. No entanto, a priori não espera-se fortes relações estatísticas, a partir desses testes, devido às variações de fatores locais que regulam a produção de sedimentos, como variações topográficas e geológicas. Ao contrário, o sistema deve ser complexo, ocorrendo interações entre as variáveis em si e com efeitos não levados em conta. Esse raciocínio levou ao entendimento de que as variáveis dependentes devem ser modeladas em um contexto multivariado. Portanto, a análise de regressão multivariada foi aplicada, em que se utilizou o método de seleção de atributos backward stepwise.

\section{Resultados e discussões}

3.1 Transporte anual de sedimentos suspensos e variabilidade interanual

O padrão espacial geral observado com relação aos valores médios de transporte anual de sedimentos é que, quanto mais à jusante, e maior a área da bacia de drenagem, maior é o transporte de sedimentos (Figura 3). Estações localizadas em seções com pequenas áreas de drenagem à montante, como aquelas situadas nos rios: Içá, Japurá, Juruá e Purus, possuem os menores valores absolutos de transporte de sedimentos. A tendência geral é que, quanto mais à jusante, o transporte de sedimentos aumenta nos principais rios devido à contribuição dos afluentes. Considerando os RAAB avaliados nesse estudo, o transporte médio aumenta em relação à área de drenagem conforme uma relação logarítmica (Figura 4).

Em alguns casos, uma grande porção da carga sedimentar pode depositar-se na planície de inundação, diminuindo o fluxo de sedimentos à jusante. Com relação às estações analisadas neste trabalho, isso é perceptível nas duas estações do rio Madeira, em que o fluxo sedimentar em Porto Velho é maior do que em Fazenda Vista Alegre. Esse padrão de diminuição da carga suspensa ao longo do baixo rio Madeira é compatível com os resultados de Espinoza Villar et al. (2013). No entanto, as séries utilizadas neste trabalho possuem uma maior extensão temporal (33 e 30 anos, Tabela 3), reforçando a compreensão do comportamento de longo prazo do sistema.

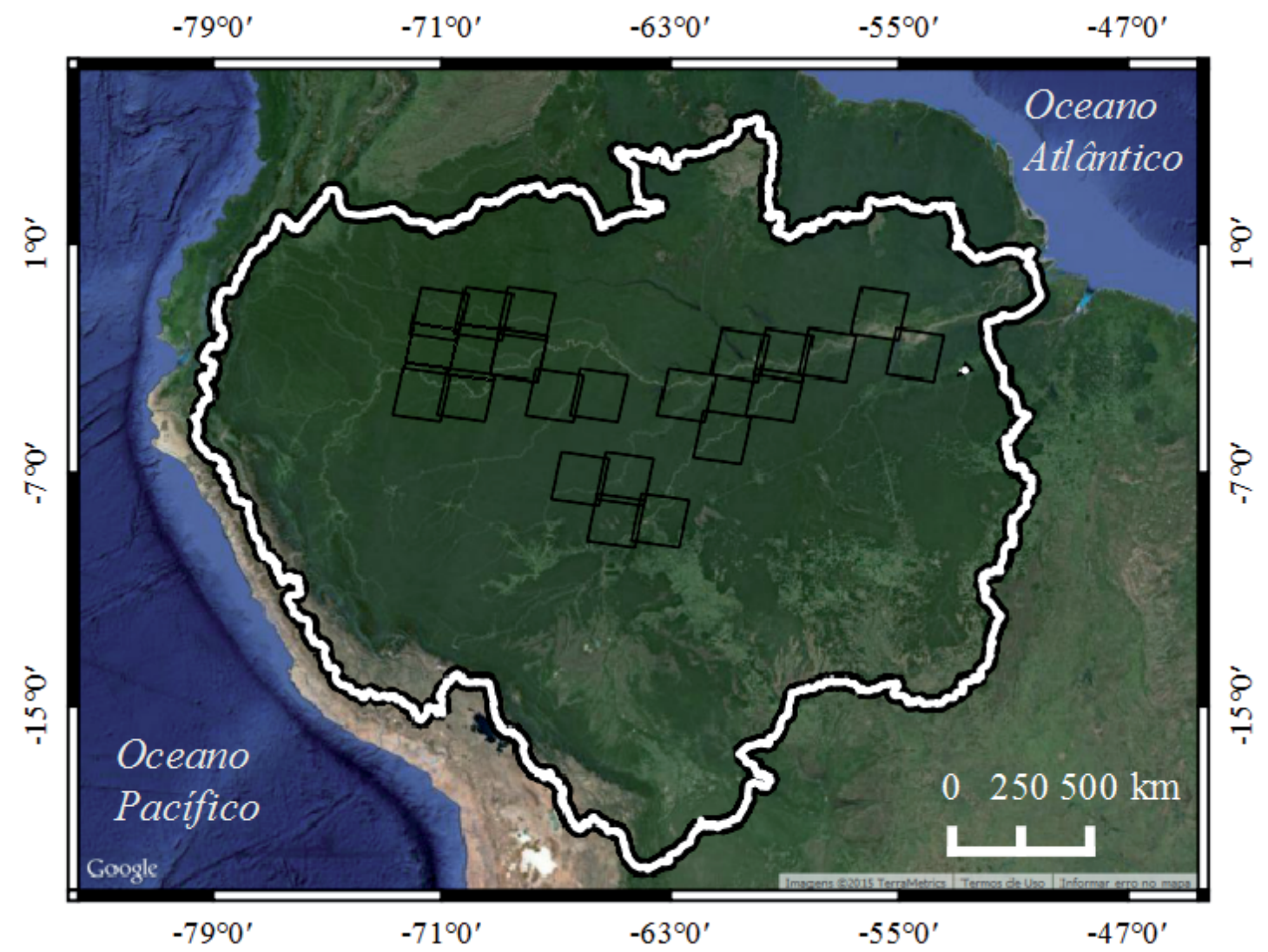

Figura 2 - Distribuição espacial de 22 cenas Landsat 5/TM utilizadas neste estudo. A linha em branco indica os limites da bacia hidrográfica amazônica. 


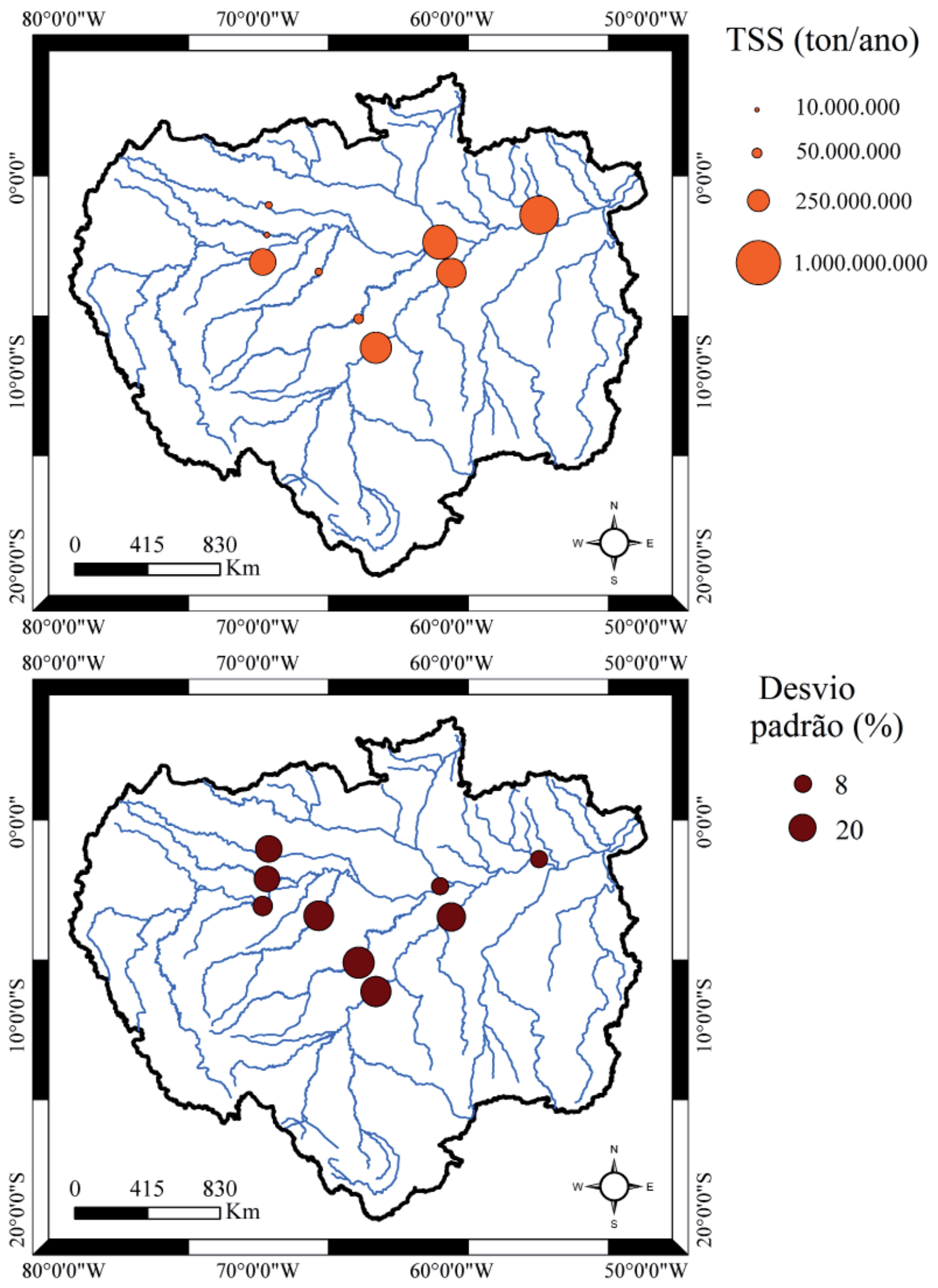

Figura 3 - Transporte de sedimentos anual médio para cada uma das nove estações (acima) e o respectivo desvio padrão anual normalizado (abaixo). 
A variabilidade interanual possui uma complexidade maior do que em relação à distribuição espacial dos totais anuais médios, sendo possivelmente explicada por mais de um fator geográfico. Um desses possíveis fatores é a latitude média da bacia, pois a variabilidade é menor em estações localizadas no centro da bacia (Figura 3), por exemplo, para as estações nos rios Solimões e Amazonas, e aumenta para maiores latitudes (norte e sul). Observa-se o aumento da variabilidade de Óbidos, no rio Amazonas, para Fazenda Vista Alegre e Porto Velho no rio Madeira (Figura 3), cada vez mais a sul. Igualmente, também observa-se um aumento de Tabatinga, no rio Solimões, para os rios Içá e Japurá, cada vez mais a norte.

A variabilidade interanual do transporte de sedimentos pode estar relacionada com a latitude devido ao fato de que a Zona de Convergência Intertropical (ZCIT) também possui uma variabilidade interanual com relação à sua região de atuação - em alguns anos ela avança mais para sul e/ou norte - (MELO et al., 2009). Por exemplo, em anos em que a ZCIT avançar mais para sul e permanecer por mais tempo nessa região, do que em anos comuns, espera-se que a precipitação, e em consequência, a produção de sedimentos nesse ano seja igualmente maior. O mesmo raciocínio aplica-se para o avanço da ZCIT para norte. De forma contrária, as regiões que estão mais centradas na área de atuação da ZCIT possuirão uma menor variabilidade interanual. Outro fenômeno atmosférico que também carrega umidade, mas apenas para sul, são os jatos de baixos níveis (JBN-MARENGO et al., 2009). Espera-se que a produção de sedimentos

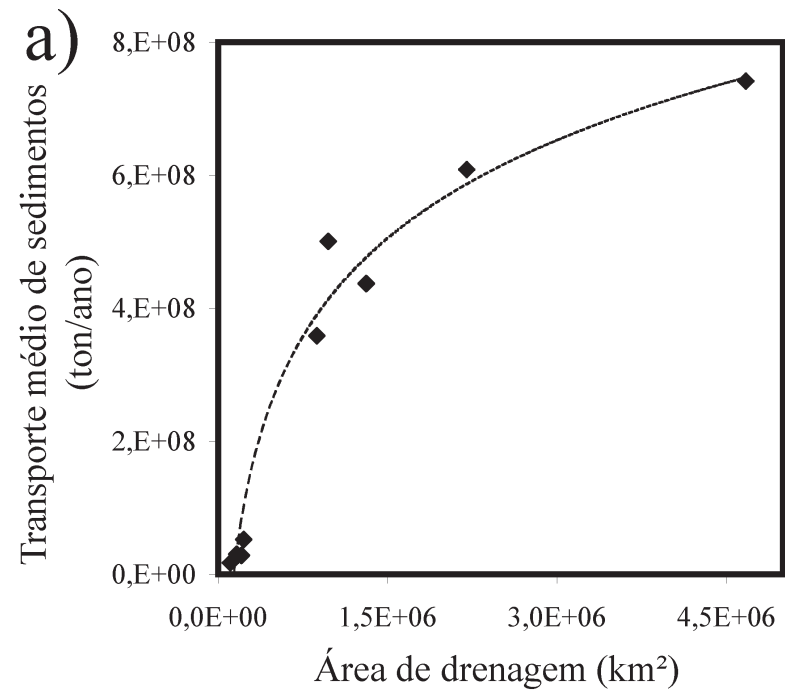

seja maior em anos com maior ocorrência e intensidade de JBN na região sul da bacia, possivelmente explicando parte da variabilidade interanual.

Outra relação possível é entre a variabilidade interanual e a longitude do ponto médio da bacia. Os Andes encontram-se dispostos como uma cadeia montanhosa em sentido norte-sul, ao passo que os rios amazônicos fluem a leste. Portanto, quanto mais a oeste está uma determinada estação, menor é a trajetória dos sedimentos transportados, o que favorece um menor tempo para que os sedimentos sejam depositados e resuspensos, aumentando assim sua variabilidade temporal, a qual é diretamente ligada com o transporte a partir das zonas de produção. Espera-se então que, quanto mais a leste, menor seja a variabilidade interanual.

Por último, quanto mais a montante situa-se uma determinada estação, menor a área de captação e maior é a exposição da superfície a eventos específicos de precipitação, que podem promover uma produção anômala de sedimentos. Portanto, a área de drenagem também pode ser uma variável explicativa da variabilidade interanual da produção de sedimentos.

A variabilidade interanual foi plotada juntamente com cada uma das três variáveis mencionadas acima, cujos resultados apontam para baixos níveis de correlação (Figuras 4 e 5). O maior índice de explicação encontrado foi entre a variabilidade e a área da bacia (Figura 5), em que o padrão observado é inverso, ou seja, quanto maior a área da bacia, menor sua variabilidade interanual de produção de sedimentos.

Figura 4 - a) Relação logarítmica entre o transporte de sedimentos suspensos anual médio e a área de drenagem à montante de cada estação; b) os mesmos dados foram plotados novamente, mas nesse caso a variável "área de drenagem" foi linearizada para aplicação da análise de regressão (valor-p $<0,001$ ). 


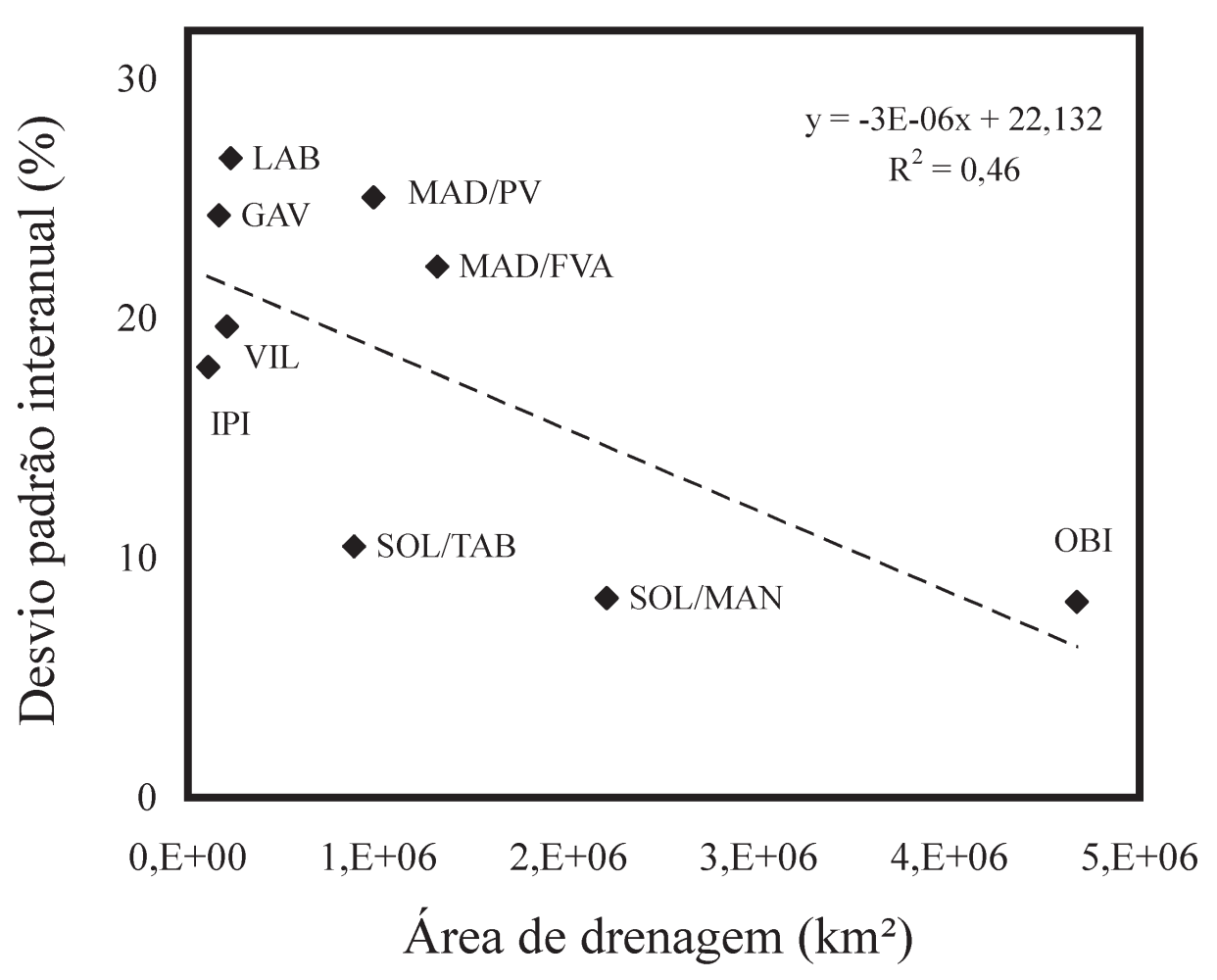

Figura 5 - Relação entre o desvio padrão interanual e a área de drenagem a montante de cada estação. LAB - Lábrea, rio Purus; GAV-Gavião, rio Juruá; VIL - Vila Bittencourt, rio Japurá; IPI - Ipiranga Velho, rio Içá; SOL/TAB - Tabatinga, rio Solimões; SOL/MAN - Manacapuru, rio Solimões; MAD/FVA - Fazenda Vista Alegre, rio Madeira; MAD/PV - Porto Velho, rio Madeira; OBI - Óbidos, rio Amazonas.

A latitude e a longitude não possuem uma relação direta (linear) com a variabilidade interanual da produção de sedimentos (Figura 6). Quando todas as estações são avaliadas conjuntamente, os fatores locais que regulam a produção de sedimentos são desconsiderados. Por exemplo, quando observa-se as duas estações do rio Madeira, aquela que está mais a leste possui uma variabilidade menor, mesmo padrão observado com relação às estações do rio Solimões e do Amazonas (Figura 6, observar as setas). As demais estações estão em rios diferentes, impossibilitando uma comparação direta, pois, cada um possui um contexto de latitude e área de drenagem. As mesmas considerações são feitas para a relação direta entre latitude e a variabilidade (Figura 6).

Embora a longitude e a área de drenagem não possuam um grande potencial explicativo da variabilidade interanual da produção de sedimentos, quando avaliadas de forma separada (Figuras 4 e 5), quando elas são avaliadas conjuntamente explicam cerca de $90 \%$ da variabilidade interanual (Figura 7). Os valores dos coeficientes mostram que a variabilidade diminui com o aumento do tamanho da área da bacia, mas há uma ponderação pela longitude, ao contrário do esperado, as bacias que possuem centro geográfico mais a leste possuem uma variabilidade maior, para uma bacia de mesma área.

\subsection{Produção de sedimentos anual média}

Enquanto que o transporte de sedimentos suspensos é maior nas estações de jusante (Figura 3), devido ao somatório das contribuições dos afluentes, a produção média das bacias possui um padrão contrário, sendo maior nas estações de montante (Figura 8). Esse padrão geral é explicado pelo alto contraste de produção de sedimentos entre os Andes e o restante da bacia. A produção sedimentar é muito baixa nos escudos cristalinos e nas planícies de inundação. Nessas últimas também ocorre a deposição de sedimentos, diminuindo o fluxo de sedimentos a jusante. Portanto, o valor da produção de sedimentos dessas regiões diminui quando suas áreas são levadas em conta.

Comparando as figuras 2 e 7, observa-se que ao norte, nas bacias dos rios Içá e Japurá, predominam baixos valores, tanto de transporte total, quanto de produção de sedimentos. Já as bacias localizadas na região controlada pelo Arco de Fitzcarraldo (rios Juruá 

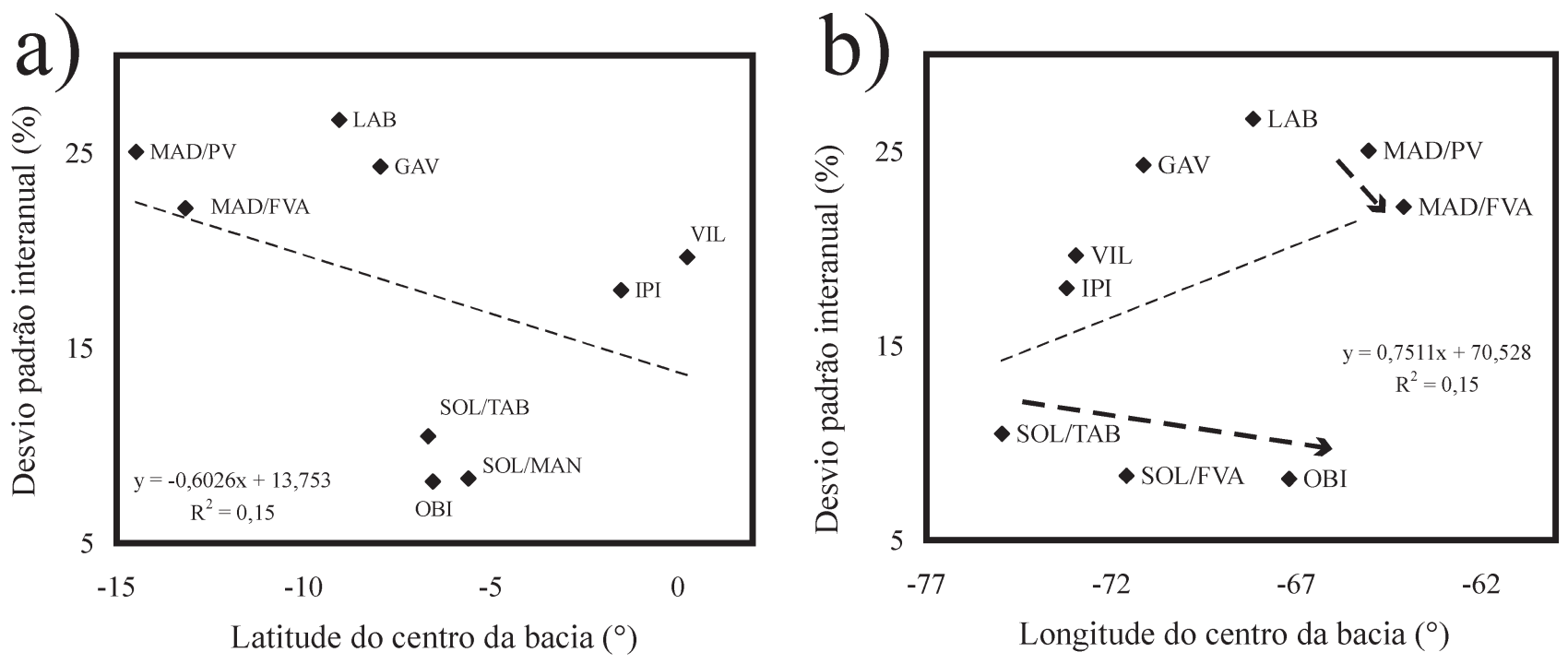

Figura 6 - Relação entre o desvio padrão interanual e a latitude do centro da bacia (a) e a longitude do centro da bacia (b). As siglas estão listadas na legenda da Figura 5.

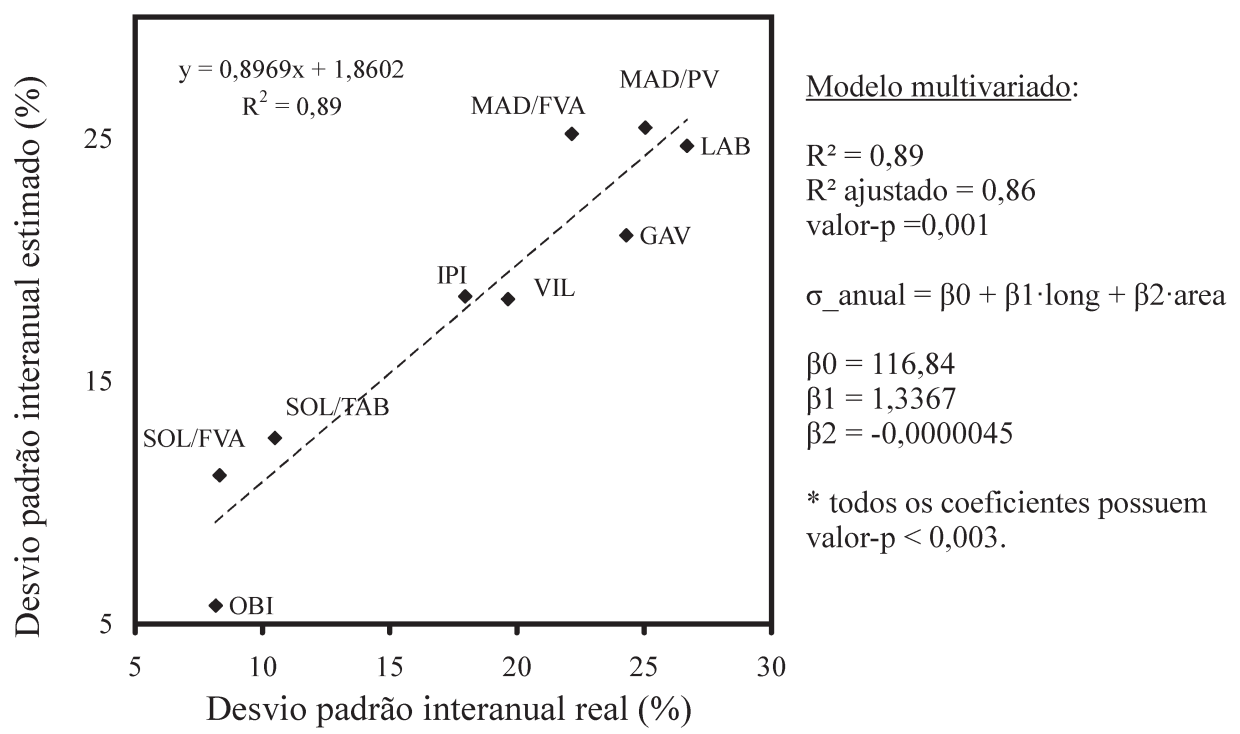

Figura 7 - Resultados da análise de regressão múltipla em que o desvio padrão interanual é a variável dependente e a longitude e a área de drenagem foram selecionados pelo backward stepwise como variáveis independentes. As siglas estão listadas na legenda da Figura 5.

e Purus), embora possuam baixos valores de transporte absoluto, quando tal transporte é ponderado pela área dessas bacias, elas mostram uma produção relativamente maior. Isso mostra o expressivo controle que o Arco de Fitzcarraldo possui sobre os processos superficiais, pois as taxas de erosão nessas áreas foram equivalentes ou maiores do que algumas regiões com cabeceiras de drenagem nos Andes. Com relação aos dois principais fornecedores de sedimentos para o rio Amazonas, enquanto que o rio Solimões é o que possui o maior transporte total, a bacia do rio Madeira apresenta os maiores valores de produção de sedimentos.

Em relação ao potencial de explicação da produção de sedimentos, levantou-se como hipótese que seu valor deve aumentar proporcionalmente com o aumento da latitude e da longitude. Nessa análise, a área de drenagem não foi adotada como variável independente porque está inserida no cálculo da produção de sedimentos (equação 2). Em relação à latitude, sabe-se que no contexto dos Andes, na região amazônica, as porções central e sul possuem maiores taxas de erosão geológica e produção de sedimentos (LATRUBESSE 
e RESTREPO, 2014). Em relação à longitude, esperase que quanto mais a oeste, maior seja a produção de sedimentos devido à proximidade com os Andes.

Os resultados da análise de regressão multivariada mostram que ambos os fatores geográficos são proporcionais à produção de sedimentos (Figura 9), e que cerca de $70 \%$ da variação é explicada por essas duas variáveis. Ainda, a latitude apresenta-se como uma variável mais importante para o modelo do que a longitude. De fato, as bacias localizadas ao sul, principalmente as do rio
Madeira, possuem altas taxas de produção de sedimentos, enquanto que aquelas situadas ao norte possuem menores intensidades de processos erosivos e, portanto, menor produção de sedimentos. No entanto, essa análise de regressão não gerou um modelo com potencial explanatório comparável aos resultados da análise da variabilidade interanual do transporte de sedimentos (Figura 7). Nesse caso, o potencial explicativo é menor, e algumas variáveis não são significativas ( $\beta 0$ e $\beta 2$ não são significativos para $\alpha=0,1$ ).

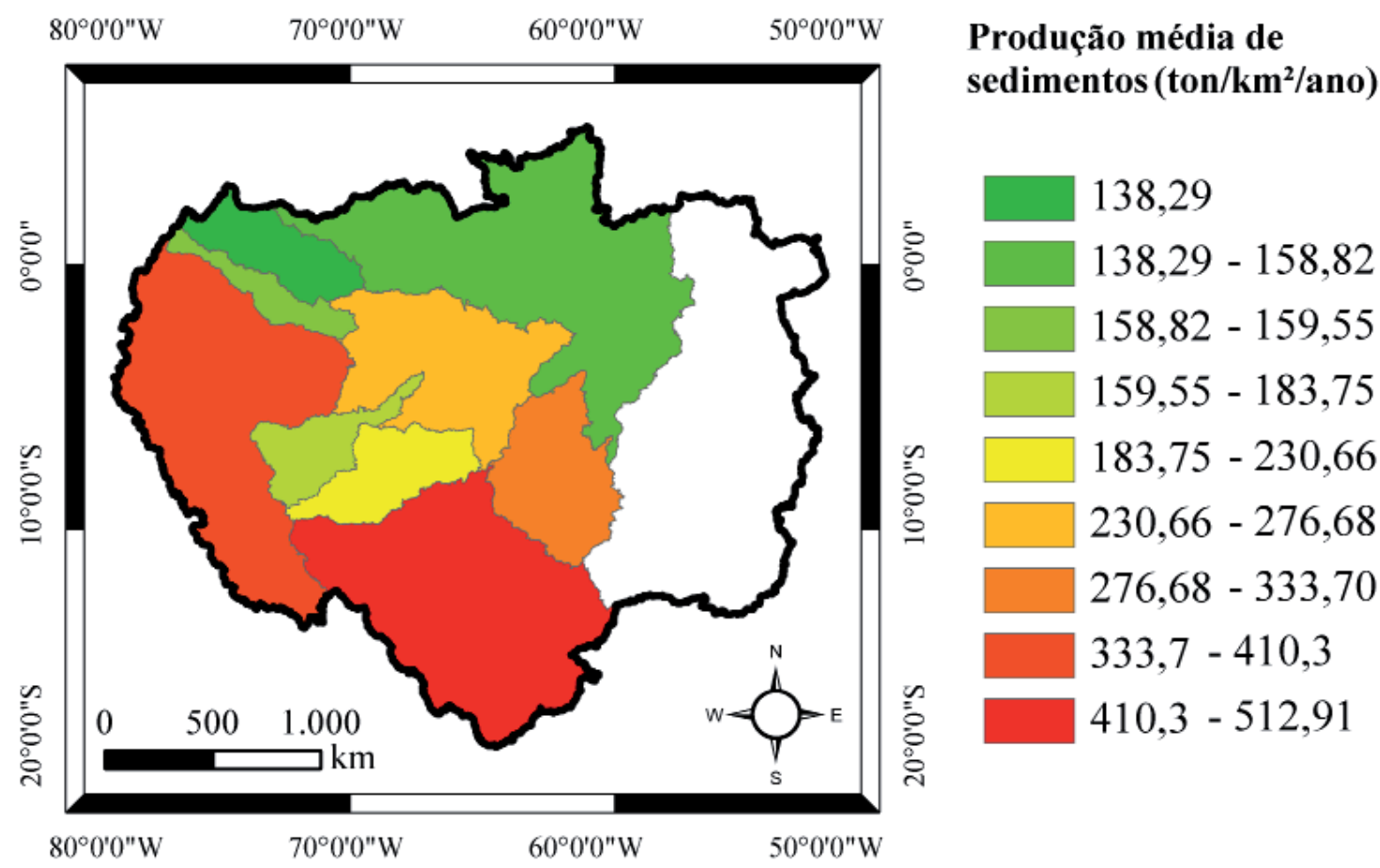

Figura 8 - Produção de sedimentos suspensos anual média dos rios amazônicos de águas brancas.

\subsection{Produção mensal média de sedimentos}

A avaliação da produção média mensal de sedimentos mostra uma grande variação ao longo da bacia em escala intranual (Figura 10). Em geral, os menores valores de produção de sedimentos concentram-se nos meses de agosto, setembro e outubro, que são os meses de menor precipitação na porção centro-sul da bacia. Há um aumento rápido da produção nos meses de novembro e dezembro, sendo o período entre janeiro e março o de maiores valores. Entre abril e julho as taxas diminuem até o próximo período de baixa produção sedimentar.

A região que produz a maior quantidade de sedimentos é a bacia do alto rio Madeira, em que grande parte da massa é transportada no período chuvoso, entre os meses de janeiro a abril. Esta bacia, no entanto, possui valores extremamente baixos nos meses secos, o que reforça o efeito latitudinal e a atuação das massas de ar sobre essa região. As bacias respectivas às estações centrais, no rio Solimões também possuem altos valores de produção de sedimentos, sendo menores do que os máximos da bacia do rio Madeira e maiores do que seus mínimos. As bacias de menor ordem, dos rios Içá, Japurá, Purus e Juruá possuem baixos valores mensais, apresentando pouco contraste ao longo do ano.

Ao contrário dos valores absolutos de transporte de sedimentos, os valores relativos (Figura 11) permitem uma síntese do comportamento intranual da bacia. É possível notar nessa figura que março é o mês em que grande parte da bacia apresenta máxima taxa de produção de sedimentos. Nesta representação também 
fica claro que os setores sul e norte da bacia possuem regimes hidrossedimentares totalmente distintos. As bacias dos rios Içá e Japurá possuem os valores mínimos entre janeiro e março e máximo entre julho e agosto, ao contrário da bacia do rio Madeira. Já a bacia do rio Solimões possui máximos que acompanham o padrão do sul da bacia, visto que grande parte dos Andes, que estão nos limites da bacia do alto rio Solimões, estão na porção sul. No entanto, esta bacia possui uma variação intranual menor, possivelmente pelo fato de que a bacia do alto Solimões também inclui outros setores dos Andes (porções central e norte da bacia).

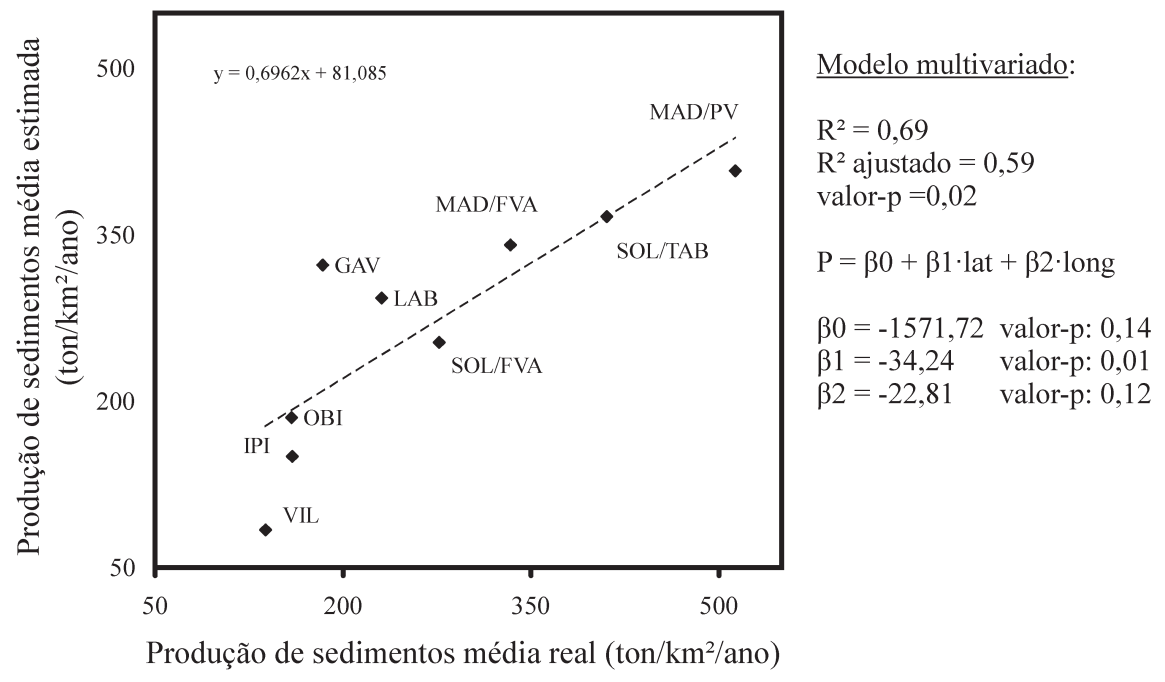

Figura 9 - Resultados da análise de regressão múltipla. A produção de sedimentos anual média é a variável dependente e a longitude e a latitude são as variáveis independentes. As siglas estão listadas na legenda da Figura 5.

\subsection{Variabilidade da produção mensal de sedimentos}

O desvio padrão mensal da produção de sedimentos possui relação com a posição latitudinal (Figura 12). As bacias das estações centrais possuem uma variabilidade menor do que aquelas nos setores norte e sul em praticamente todo o ano. Isso está ligado possivelmente com a variação da atuação da ZCIT em cada ano. Assim como em relação aos valores de produção de sedimentos, novamente há distintos padrões quando se compara a variabilidade mensal dos extremos latitudinais. Nas bacias da região norte a variabilidade é maior nos meses entre janeiro e março e no sul é maior entre julho e novembro. Esses são os períodos de mais baixa produção nas duas regiões. Como a variabilidade é expressa em termos relativos (\%), pequenas variações de transporte entre um mês qualquer e sua média introduzem grandes variações relativas.

Outra característica do padrão espacial da produção de sedimentos é que, quanto mais próximo da área-fonte de sedimentos, maior é a variabilidade mensal. Observase, por exemplo, que a variabilidade em Óbidos é a menor da bacia, que a estação de Fazenda Vista Alegre registra uma menor variação do que em Porto Velho (rio Madeira) e que a estação de Tabatinga registra uma variação maior do que em Manacapuru (rio Solimões), todos os casos em quase todo o ano (Figura 12). Isso deve ser explicado pelos processos de deposição e ressuspensão que ocorrem nas planícies, que devem normalizar variações anômalas da produção de sedimentos nas áreas-fonte.

Observou-se a relação entre longitude, latitude, a área de cada bacia e suas variabilidades mensais médias. Isoladas, essas variáveis possuem baixa capacidade explicativa (longitude: $\mathrm{R}^{2}=0,27$; latitude: $\mathrm{R}^{2}=$ 0,31 ; longitude: $\mathrm{R}^{2}=0,29$ ), em que nenhuma variável é significativa para $\alpha=0,1$. Da mesma forma que nos outros testes, foi aplicada uma análise de regressão multivariada entre as variáveis geográficas e a variabilidade mensal, que resultou no modelo apresentado na Figura 13. Nesse caso, a longitude e a área foram selecionadas, todas significativas para $\alpha=0,01$. Da mesma forma que o modelo para determinação da variabilidade anual do transporte de sedimentos (Figura 7), os coeficientes mostram que quanto maior a área da bacia, e quanto mais a oeste, menor a variabilidade da produção de sedimentos. 


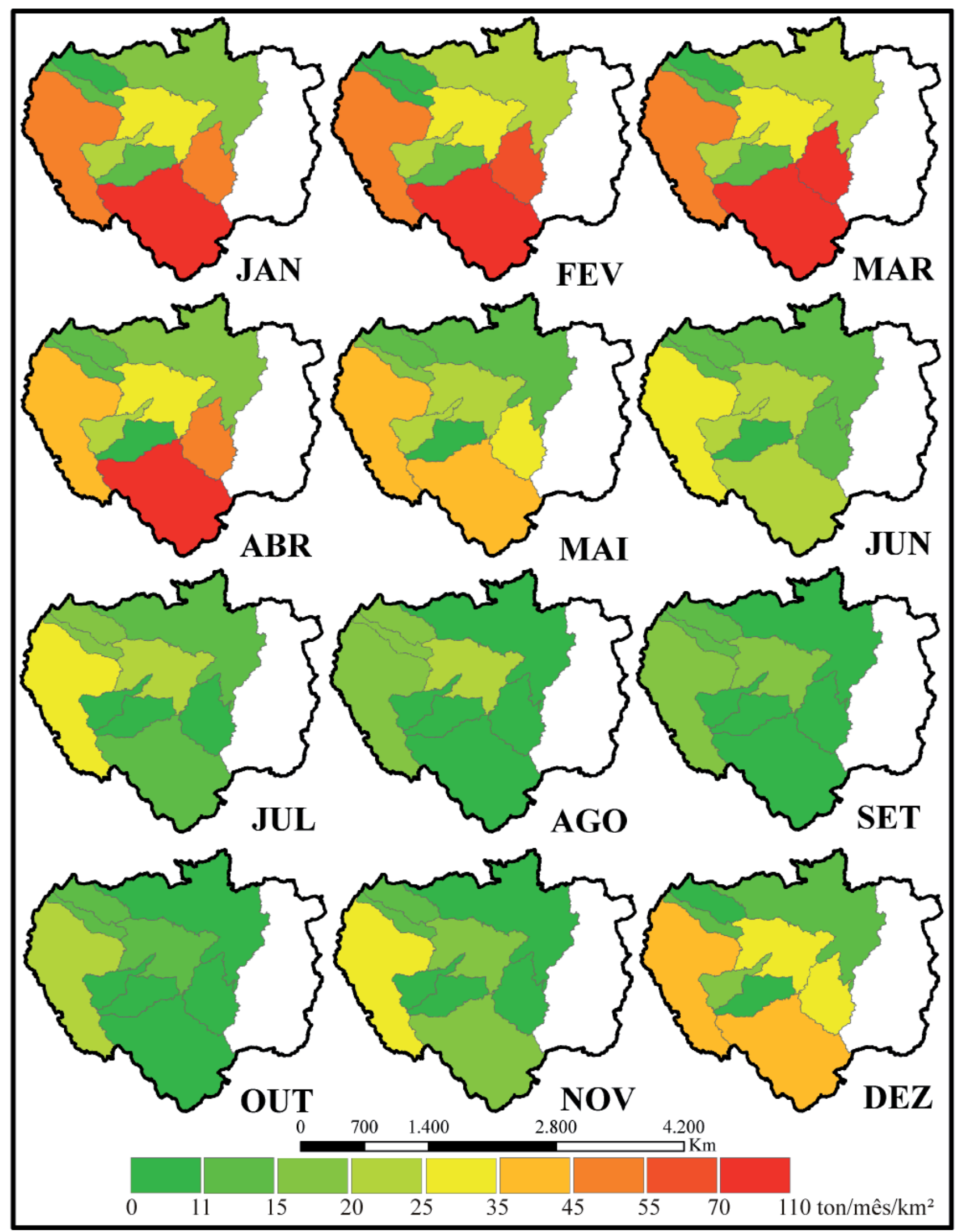

Figura 10 - Produção de sedimentos mensal média dos rios amazônicos de águas brancas. 


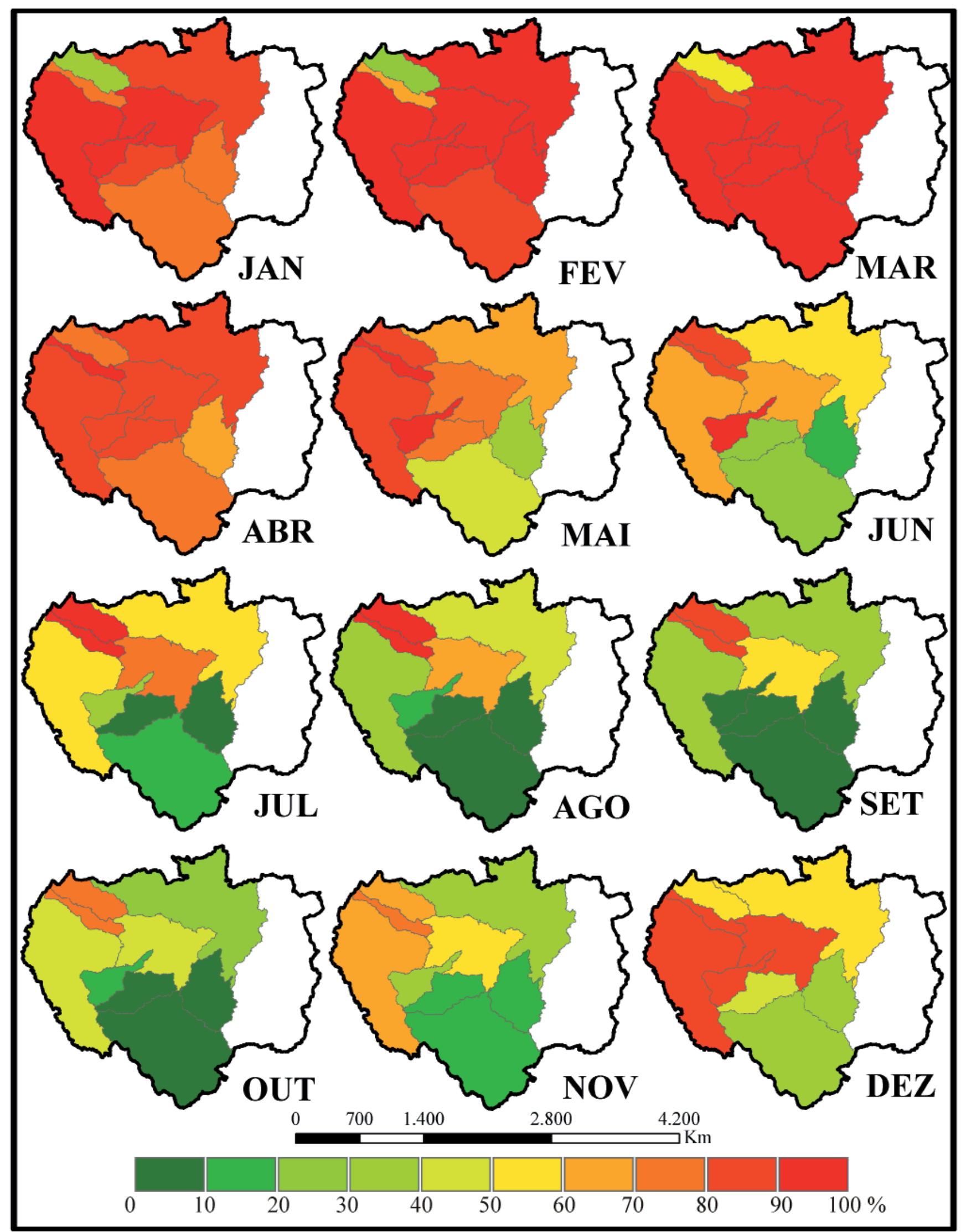

Figura 11 - Produção de sedimentos mensal média normalizada dos rios amazônicos de águas brancas. 


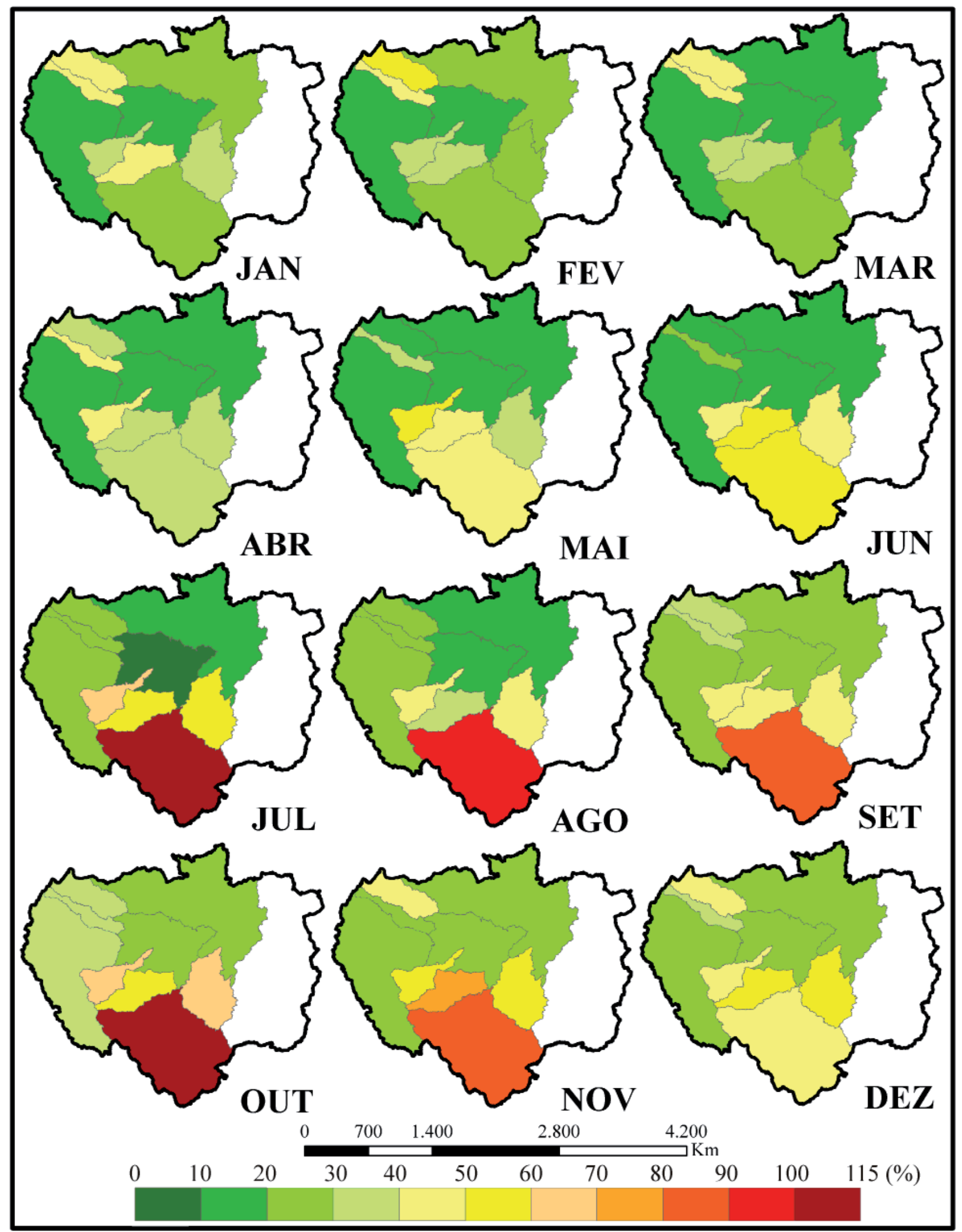

Figura 12 - Produção de sedimentos mensal média normalizada dos rios amazônicos de águas brancas. 
De fato, as variabilidades mensais e anuais possuem uma forte relação entre si (Figura 14), o que reforça os resultados das análises de regressão multivariada, de que ambas possuem os mesmos fatores de origem (longitude e área de drenagem da bacia). Outro aspecto relevante a ser notado na Figura 14 é a diferença em termos de magnitude. Enquanto a variabilidade anual das bacias oscila entre $8 \%$ e $26 \%$, os valores de variabilidade mensal possuem maior amplitude, indo de $15 \%$ a $65 \%$. Isso se deve ao aumento da escala temporal no caso dos valores anuais, a qual tende a compensar as mensais extremas provocadas pela sazonalidade do regime hidrológico das diferentes bacias.

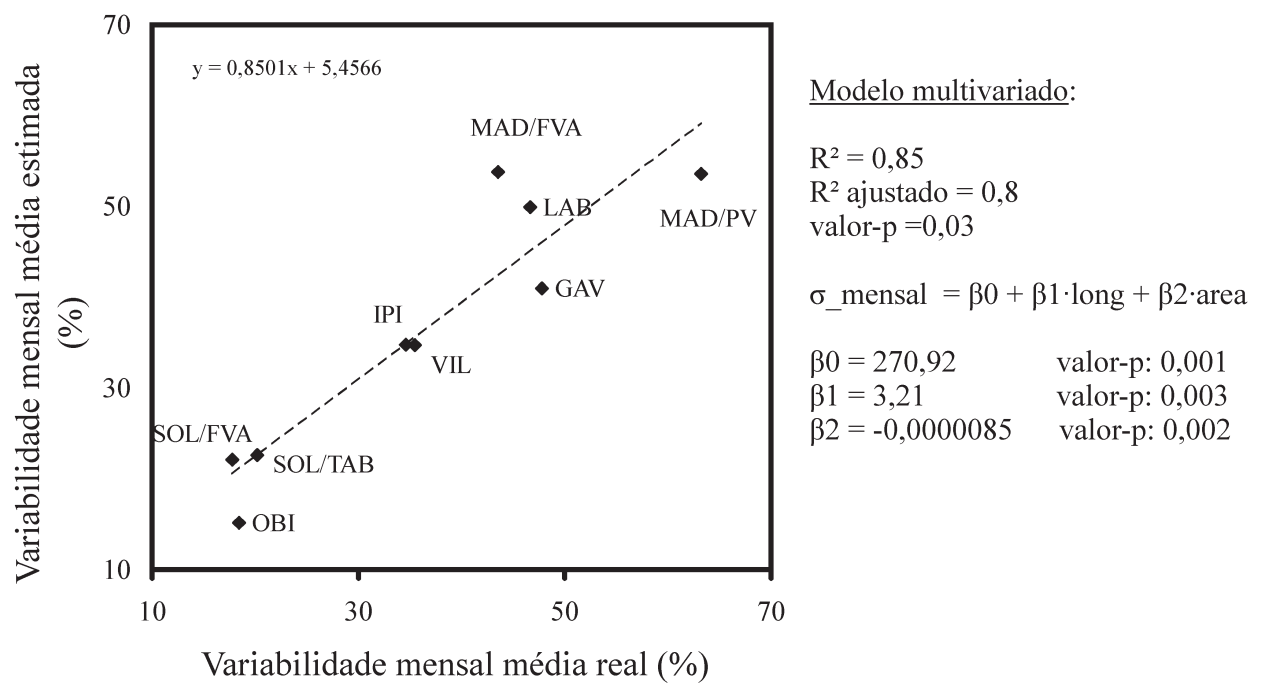

Figura 13 - Produção de sedimentos mensal média normalizada dos rios amazônicos de águas brancas. As siglas estão listadas na legenda da Figura 5.

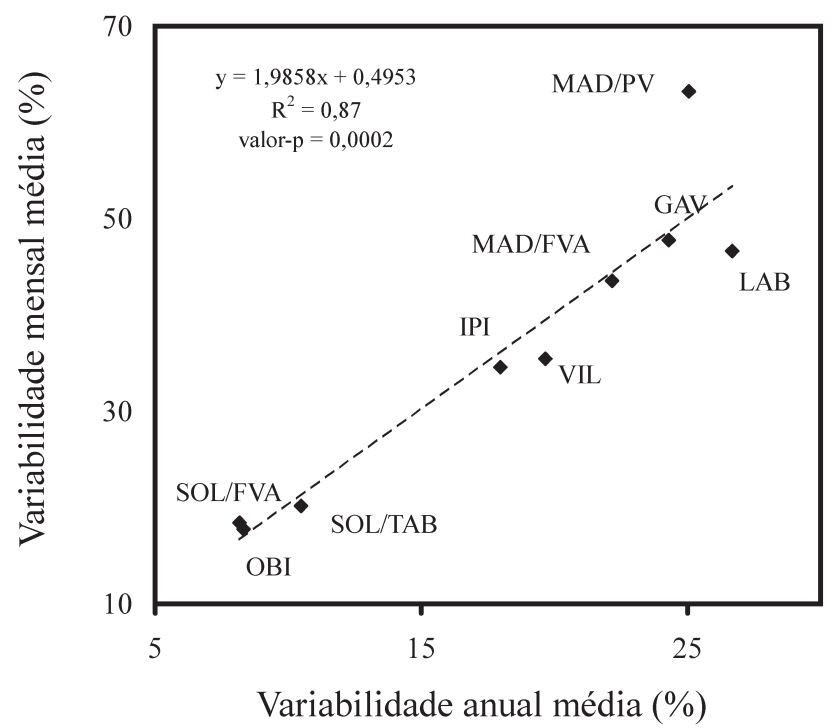

Figura 14 - Produção de sedimentos mensal média normalizada dos rios amazônicos de águas brancas. As siglas estão listadas na legenda da Figura 5.

\section{Conclusões}

Os resultados obtidos permitem as seguintes conclusões em relação aos padrões espaciais e relações determinantes:
- Transporte de sedimentos anual médio: quanto mais à jusante, e maior a área da bacia de drenagem, maior é o transporte de sedimentos, devido às somas de contribuições dos afluentes. Esse padrão 
não foi verdadeiro apenas para o rio Madeira, onde há uma importante zona de deposição entre Porto Velho (montante) e Fazenda Vista Alegre (jusante). Também foi observado que esse transporte aumenta em relação à área de drenagem conforme uma relação logarítmica.

- Produção de sedimentos anual média: enquanto o transporte de sedimentos suspensos é maior nas estações de jusante, a produção média das bacias possui um padrão contrário, sendo maior nas estações de montante. Tanto a latitude quanto a longitude são proporcionais com a produção de sedimentos (maior produção de sedimentos para sul e oeste). Cerca de $70 \%$ da variação é explicada por essas duas variáveis, em que a latitude apresenta-se como uma variável mais importante para o modelo do que a longitude (única variável significativa para $\alpha=0,05$ ).

- Produção de sedimentos mensal média: Considerando toda a bacia, os menores valores de produção de sedimentos concentram-se no período entre os meses de agosto e outubro, e o período que possui os maiores valores é entre janeiro e março. A região que produz a maior quantidade de sedimentos é a bacia do alto rio Madeira, em que grande parte da massa é transportada no período chuvoso, entre os meses de janeiro a abril. Esta bacia, no entanto, possui valores extremamente baixos nos meses secos.

- Ao contrário dos valores absolutos de transporte de sedimentos, os valores relativos permitem uma síntese do comportamento temporal intranual da bacia. Sua análise mostra que os setores sul e norte da bacia possuem regimes hidrossedimentares distintos. As bacias dos rios Içá e Japurá possuem os menores valores no período entre janeiro e março e máximo entre julho e agosto, ao contrário da bacia do rio Madeira.

- Variabilidade temporal: as estações que estão no centro da bacia possuem uma menor variabilidade temporal, tanto interanual quanto mensal. As variabilidades anuais e mensais possuem uma forte relação e foram explicadas pelas mesmas variáveis (área de drenagem e longitude). Os coeficientes da regressão mostram que, quanto maior a área da bacia, e quanto mais a oeste, menor a variabilidade temporal da produção de sedimentos.

\section{Agradecimentos}

Este artigo faz parte da pesquisa de doutorado do primeiro autor, que agradece a bolsa de estudos concedida pelo CNPq, processo $n^{\circ}$ 141658/2014-2. Também agradecemos à política de distribuição livre de dados, adotada pelo INPE, ANA, ORE HYBAM e IDEAM.

\section{Referências Bibliográficas}

AALTO, R.; DUNNE, T.; GUYOT, J. L. Geomorphic controls on Andean denudation rates. Journal of Geology, vol. 114, p. 85-99, 2006.

AB'SÁBER, A. Os domínios de natureza no Brasil: Potencialidades paisagísticas. São Paulo: Ateliê editorial, 5 ed., 2008. 160 p.

ARMIJOS, E.; CRAVE, A.; VAUCHEL, P.; FRAIZY, P.; SANTINI, W.; MOQUET, J. S.; AREVALO, N.; CARRANZA, J.; GUYOT, J. L. Suspended sediment dynamics in the Amazon River of Peru. Journal of South American Earth Sciences, vol. 44, p. 75-84, 2013.

BOOKHAGEN, B.; STRECKER, M. R. Modern Andean rainfall variation during ENSO cycles and its impact on the Amazon drainage basin. In: HOORN, C.; WESSELINGH, F. P., (Eds). Amazonia, Landscape and Species evolution: A look into the past. 1 ed. Blackwell Publishing, 2010.

CONSTANTINE, J. A.; DUNNE, T.; AHMED, J.; LEGLEITER, C.; LAZARUS, E.D. Sediment supply as a driver of river meandering and floodplain evolution in the Amazon basin. Nature Geoscience, vol. 7, p. 899 - 903, 2014.

DUNNE, T.; MERTES, L. A. K.; MEADE, R. H.; RICHEY, J. E.; FORSBERG, B. R. Exchanges of sediment between the flood plain and channel of the Amazon River in Brazil. Bulletin of the Geological Society of America, vol. 110, n. 4, p. 450 467, 1998.

ESPINOZA VILLAR, R.; MARTINEZ, J. M.; GUYOT, J. L.; FRAIZY, P.; ARMIJOS, E.; CRAVE, A.; BAZÁN, H.; VAUCHEL, P.; LAVADO, W. The integration of field measurements and satellite observations to determine river solid loads in poorly monitored basins. Journal of Hydrology, vol. 444, p. 221-228, 2012.

ESPINOZA VILLAR, R.; MARTINEZ, J. M.; TEXIER, M. L.; GUYOT, J. L.; FRAIZY, P.; MENESES, P. R.; OLIVEIRA, E. A study of sediment transport in the Madeira River, Brazil, using MODIS remote-sensing images. Journal of South American Earth Sciences, vol. 44, p. 45 - 54, 2013. 
ESPURT, N.; BABY, P.; BRUSSET, S.; RODDAZ, M.; HERMOZA, R. V.; ANTOINE, P. O.; SALAS-GISMONDI, R.; BOLÃNOS, R. How does the Nazca Ridge subduction influence the modern Amazonian foreland basin? Geology, vol. 35, p. 515-518, 2007.

FILIZOLA, N. O fluxo de sedimentos em suspensão nos rios da Bacia Amazônica brasileira. ANEEL, 63 p. 1999.

FILIZOLA, N.; GUYOT, J. L. Fluxo de sedimentos em suspensão nos rios da Amazônia. Revista Brasileira de Geociências, vol. 41, n. 4, p. $566-576,2011$.

FILIZOLA, N.; GUYOT, J. L.; WITTMANN, H.; MARTINEZ, J. M.; OLIVEIRA, E. The significance of suspended sediment transport determination on the Amazonian hydrological scenario. In: Manning AJ. (Editor). Sediment Transport in Aquatic Environments. INTECH Open Access Publisher. DOI: 10.5772/19948, 2011.

GIBBS, R. J. Amazon rivers: environmental factors that control its dissolved and suspended load. Science, vol. 156, p. 1734 $-1737,1967$

GUYOT, J. L.; FILIZOLA, N.; LARAQUE, A. Régime et bilan du flux sédimentaire de l'Amazone à Óbidos (Pará, Brésil) de 1995 à 2003. In: Sediment Budget symposium held during the Seventh IAHS Scientific Assembly. Anais... v. 291. IAHS Publication, Foz do Iguaçu, p. 347 -354, 2005.

GUYOT, J. L. et al., Hydrology and sediment transport in the Amazon basin, from the Andes to the ocean. In: World's Large Rivers Conference. Anais... Vienna, 2011.

JUNK, W.; PIEDADE, M. T. F.; SCHÖNGART, J.; COHNHAFT, M.; ADENEY, J. M.; WITTMANN, F. A classification of major naturally-occurring Amazonian lowland wetlands. Wetlands, vol. 31, n. 4, p. 623 - 640, 2011.

KILHAM, N. E.; ROBERTS, D. Amazon river time series of surface sediment concentration from MODIS. International Journal of Remote Sensing, vol. 32, n. 10, p. 2659-2679, 2011.

LARAQUE, A.; FILIZOLA, N.; GUYOT, J. L. Variations spatiotemporelles du bilan sédimentaire dans le bassin amazonien brésilien, à partir d'un échantillonnage décadaire. In: Walling, D. E., Horowitz, A. J. (Eds.), Sediment Budgets 1, vol. 291. IAHS Publ., p. 250-258. 2005.

LATRUBESSE, E.; RESTREPO, J. D. Sediment yield along the Andes: continental budget, regional variations, and comparisons with other basins from orogenic mountain belts. Geomorphology, vol. 216, p. 225 - 233, 2014.

LOBO, F. L.; COSTA, M. P. F.; NOVO, E. M. L. M. Time-series analysis of Landsat-MSS/TM/OLI images over Amazonian Waters impacted by gold mining activities. Remote Sensing of Environment, vol. 117, p. 57 - 71, 2014.

MARENGO, J. A.; AMBRIZZI, T.; SOARES, W.R Jato de baixos níveis ao longo dos Andes. In: Cavalcanti et al., (org.) Tempo e clima no Brasil. São Paulo: Oficina de Textos, 2009.

MARTINELLI, L. A.; VICTORIA, R. L.; DEVOL, A. H.; FOSBERG, B. R. Suspended load in the Amazon Basin: An Overview. GeoJournal, vol. 19, n. 4, p. 381 - 389, 1989.

MARTINEZ, J. M.; GUYOT, J. L.; FILIZOLA, N.; SONDAG, F. Increase in suspended sediment discharge of the Amazon River assessed by monitoring network and satellite data. Catena, vol. 79, n. 3, p. 257 - 264, 2009.

McCLAIN, M. E.; NAIMAN, R. J. Andean Influences on the biogeochemistry and ecology of the Amazon River. BioScience, vol. 58, n. 4, p. 325-338, 2008.

MEADE, R. H. Suspended sediments of the modern Amazon and Orinoco rivers. Quaternary International, vol. 21, p. 29 $-39,1994$

MEADE, R. H. Transcontinental moving and storage: the Orinoco and Amazon rivers transfer the Andes to the Atlantic. In: Gupta, A. (Editor), Large rivers: Geomorphology and management. John Wiley \& Sons, 2007.

MEADE, R. H.; NORDIM, C. F. J.; CURTIS, W. F.; RODRIGUES, F. M. C.; VALE, C. W.; EDMOND, J. M. Sediment loads in the Amazon River. Nature, vol. 278, n. 8, p. $161-163,1979$.

MEADE, R. H.; DUNNE, T.; RICHEY, J. E.; SANTOS, U. M.; SALATI, E. Storage and remobilization of suspended sediment in the lower Amazon River of Brazil. Science, vol. 228, p. 488 $-490,1985$.

MELO, A. B. C.; CAVALCANTI, I. F. A.; SOUZA, P. P. Zona de Convergência Intertropical do Atlântico. In: Cavalcanti et al., (org.) Tempo e clima no Brasil. São Paulo: Oficina de Textos, 2009.

MONTANHER, O. C. Modelos empíricos para estimativa da concentração de sedimentos em suspensão em rios amazônicos de águas brancas a partir de imagens Landsat 5. 2013. 115f. Dissertação (Mestrado em Sensoriamento Remoto) - Instituto Nacional de Pesquisas Espaciais, São José dos Campos - SP. 2013.

MONTANHER, O. C.; NOVO, E. M. L. M.; BARBOSA, C. C. F.; RENNO, C. D.; SILVA, T. S. F. Empirical models for estimating the suspended sediment concentration in Amazonian 
white water rivers using Landsat/TM. International Journal of Applied Earth Observation and Geoinformation, vol. 29, p. 67-77, 2014.

NITTROUER, C. A.; KUEHL, S. A.; STERNBERG, R. W.; FIGUEIREDO, A. G.; FARIA, L. E. C. An introduction to the geological significance of sediment transport and accumulation on the Amazon continental shelf. Marine Geology, vol. 125, p. $177-192,1995$.
RÄSÄNEN, M. E.; SALO, J. S., KALLIOLA, R. J. Fluvial perturbance in the western Amazon basin: regulation by longterm sub-Andean tectonics. Science, vol. 238, p. 1398-1401, 1987.

SIOLI, H. The Amazon and its main affluents: hydrography, morphology of the river courses, and river types. In: The Amazon (pp. 127-165). Springer Netherlands. 1984. 